\title{
Advances in Antiwolbachial Drug Discovery for Treatment of Parasitic Filarial Worm Infections
}

\author{
Malina A. Bakowski * (D) and Case W. McNamara *(iD) \\ Calibr at Scripps Research, La Jolla, CA 92037, USA \\ * Correspondence: mbakowski@scripps.edu (M.A.B.); cmcnamara@scripps.edu (C.W.M.); \\ Tel.: +1-858-242-1077 (C.W.M.)
}

Received: 3 June 2019; Accepted: 11 July 2019; Published: 18 July 2019

\begin{abstract}
The intracellular bacteria now known as Wolbachia were first described in filarial worms in the 1970s, but the idea of Wolbachia being used as a macrofilaricidal target did not gain wide attention until the early 2000s, with research in filariae suggesting the requirement of worms for the endosymbiont. This new-found interest prompted the eventual organization of the Anti-Wolbachia Consortium (A-WOL) at the Liverpool School of Tropical Medicine, who, among others have been active in the field of antiwolbachial drug discovery to treat filarial infections. Clinical proof of concept studies using doxycycline demonstrated the utility of the antiwolbachial therapy, but efficacious treatments were of long duration and not safe for all infected. With the advance of robotics, automation, and high-speed computing, the search for superior antiwolbachials shifted away from smaller studies with a select number of antibiotics to high-throughput screening approaches, centered largely around cell-based phenotypic screens due to the rather limited knowledge about, and tools available to manipulate, this bacterium. A concomitant effort was put towards developing validation approaches and in vivo models supporting drug discovery efforts. In this review, we summarize the strategies behind and outcomes of recent large phenotypic screens published within the last 5 years, hit compound validation approaches and promising candidates with profiles superior to doxycycline, including ones positioned to advance into clinical trials for treatment of filarial worm infections.
\end{abstract}

Keywords: Wolbachia; filaria; parasitic worms; Onchocerca; Brugia; drug discovery; antiwolbachial; endosymbiont; neglected tropical disease; high-throughput screening

\section{Introduction}

Filarial parasitic worm infections afflict millions of people worldwide. These diseases are not commonly lethal, but the associated morbidities can cause significant physical, psychological and economic suffering for infected individuals, families, and communities. The prolonged chronic nature of infections and propensity for causing irreversible damage further compounds the negative impact of these diseases. Filarial worms of greatest concern to global health include Onchocerca volvulus, the causative agent of onchocerciasis (river blindness), and Wuchereria bancrofti, Brugia malayi and Brugia timori that are the causative agents of lymphatic filariasis (elephantiasis) (listed in Table 1 with other species relevant to the antiwolbachial approach, either as targets or model organisms). Most $O$. volvulus infections occur in sub-Saharan Africa, with small foci of infection occurring in South America and Yemen. Altogether, 205 million people live in areas where they are at risk of becoming infected and about half a million are estimated to be blinded by the disease. Lymphatic filariasis is endemic in an even greater geographic area, found in the tropics of Asia, Africa, the Pacific, and Americas, with 886 million people at risk of infection and 40 million with disfiguring and disabling physical symptoms. 
Table 1. Overview of parasitic filarial nematodes pertinent to the antiwolbachial approach.

\begin{tabular}{|c|c|c|c|c|c|c|c|c|}
\hline Filarial Nematode & Common Host & Wolbachia & Vector & Disease & Location in Host & $\begin{array}{l}\text { General } \\
\text { Symptoms }\end{array}$ & $\begin{array}{l}\text { Geographical } \\
\text { Distribution }\end{array}$ & Ref. \\
\hline Onchocerca volvulus & humans & yes & $\begin{array}{l}\text { black flies, } \\
\text { Simulium spp. }\end{array}$ & $\begin{array}{l}\text { onchocerciasis, } \\
\text { aka. river } \\
\text { blindness }\end{array}$ & $\begin{array}{l}\text { adults in subcutaneous } \\
\text { nodules, mf migrate } \\
\text { through skin and eyes }\end{array}$ & $\begin{array}{l}\text { skin disease (onchodermatitis: } \\
\text { itching, depigmentation), } \\
\text { onchocercomata (nodules), } \\
\text { blindness, neurological disease } \\
\text { (nodding syndrome, Nakalanga } \\
\text { syndrome, epilepsy) }\end{array}$ & $\begin{array}{l}\text { sub-Saharan Africa, } \\
\text { small foci in South } \\
\text { America and Yemen }\end{array}$ & {$[1,2]$} \\
\hline Onchocerca ochengi & $\begin{array}{l}\text { cattle } \\
\text { (experimental models: mice) }\end{array}$ & yes & $\begin{array}{l}\text { black flies, } \\
\text { Simulium spp. }\end{array}$ & $\begin{array}{l}\text { onchocerciasis } \\
\text { aka. } \\
\text { onchocercosis }\end{array}$ & $\begin{array}{l}\text { adults in intradermal } \\
\text { nodules, occasionally in } \\
\text { subcutis }\end{array}$ & $\begin{array}{l}\text { intradermal nodules (noted due to } \\
\text { damage to bovine hides); other } \\
\text { clinical impact unknown }\end{array}$ & $\begin{array}{l}\text { documented in } \\
\text { Uganda and } \\
\text { Cameroon; used as a } \\
\text { model to study filarial } \\
\text { infection }\end{array}$ & {$[3,4]$} \\
\hline Wuchereria bancrofti & humans ( $~ 90 \%$ of LF cases) & yes & \multirow[t]{4}{*}{ mosquitoes } & $\begin{array}{l}\text { lymphatic } \\
\text { filariasis, aka. } \\
\text { Bancroftian } \\
\text { filariasis }\end{array}$ & \multirow{4}{*}{$\begin{array}{l}\text { adults in lymphatic } \\
\text { vessels; mf in peripheral } \\
\text { blood with varying } \\
\text { periodicities }\end{array}$} & \multirow{4}{*}{$\begin{array}{l}\text { mostly asymptomatic but with time } \\
\text { cause damage to lymphatic system } \\
\text { and kidneys; } \\
\text { chronic symptoms include } \\
\text { lymphoedema, elephantiasis, } \\
\text { hydroceles;acute symptoms include } \\
\text { local inflammation, fevers, } \\
\text { secondary bacterial infections, acute } \\
\text { filarial lymphangitis, acute } \\
\text { dermatolymphangioadenitis }\end{array}$} & $\begin{array}{l}\text { tropics in Asia, Africa, } \\
\text { Pacific, and Americas }\end{array}$ & \multirow[t]{4}{*}[1,5-10]{} \\
\hline Brugia malayi & $\begin{array}{l}\text { humans (experimental } \\
\text { models: mice, jirds) }\end{array}$ & yes & & \multirow{3}{*}{$\begin{array}{l}\text { lymphatic } \\
\text { filariasis, aka. } \\
\text { Brugian } \\
\text { filariasis }\end{array}$} & & & East and South Asia & \\
\hline Brugia timori & humans & yes & & & & & $\begin{array}{l}\text { Indonesia and } \\
\text { Timor-Leste }\end{array}$ & \\
\hline Brugia pahangi & $\begin{array}{l}\text { cats, dogs, rarely humans } \\
\text { (experimental models: jirds) }\end{array}$ & yes & & & & & $\begin{array}{l}\text { Malaysia, Thailand, } \\
\text { and Indonesia }\end{array}$ & \\
\hline Mansonella ozzardi & humans & yes & $\begin{array}{l}\text { biting midges } \\
\text { (mostly } \\
\text { Culicoides) and } \\
\text { black flies, } \\
\text { Simulium spp. }\end{array}$ & $\begin{array}{l}\text { ozzardi } \\
\text { mansonellosis }\end{array}$ & $\begin{array}{l}\text { uncertain; adults } \\
\text { potentially in } \\
\text { subcutaneous } \\
\text { tissues/thoracic and } \\
\text { peritoneal cavity; mf in } \\
\text { blood and skin }\end{array}$ & $\begin{array}{l}\text { potential ocular lesions; mostly } \\
\text { asymptomatic but also fever, } \\
\text { headaches, itching, joint pain, rash, } \\
\text { sensation of coldness in the legs, foot } \\
\text { and face edema, keratitis }\end{array}$ & $\begin{array}{l}\text { Caribbean, the } \\
\text { Amazon, border } \\
\text { between Bolivia and } \\
\text { Argentina }\end{array}$ & {$[11,12]$} \\
\hline Mansonella perstans & humans and primates & $\begin{array}{l}\text { yes (potentially } \\
\text { strain } \\
\text { dependent) }\end{array}$ & $\begin{array}{l}\text { biting midges } \\
\text { (Culicoides) }\end{array}$ & mansonellosis & $\begin{array}{l}\text { adults in serous body } \\
\text { cavities, may also } \\
\text { appear subcutaneously; } \\
\text { mf in blood }\end{array}$ & $\begin{array}{l}\text { mostly asymptomatic; occasionally } \\
\text { Calabar swellings, itching, pruritus, } \\
\text { joint pain, enlarged lymph glands, } \\
\text { neurological symptoms }\end{array}$ & $\begin{array}{l}\text { western, eastern, } \\
\text { central Africa; } \\
\text { equatorial Brazil to } \\
\text { Caribbean } \\
\end{array}$ & {$[13,14]$} \\
\hline $\begin{array}{l}\text { Mansonella } \\
\text { streptocerca }\end{array}$ & humans and primates & not reported & $\begin{array}{l}\text { biting midges } \\
\text { (Culicoides) }\end{array}$ & mansonellosis & $\begin{array}{l}\text { adults in subcutaneous } \\
\text { tissues; } \mathrm{mf} \text { in skin }\end{array}$ & $\begin{array}{l}\text { mostly asymptomatic; occasionally } \\
\text { dermatitis, pruritus, rash, papular } \\
\text { skin, inguinal adenopathy, dizziness }\end{array}$ & $\begin{array}{l}\text { western, eastern, } \\
\text { central Africa }\end{array}$ & [13] \\
\hline
\end{tabular}


Table 1. Cont.

\begin{tabular}{|c|c|c|c|c|c|c|c|c|}
\hline Filarial Nematode & Common Host & Wolbachia & Vector & Disease & Location in Host & $\begin{array}{l}\text { General } \\
\text { Symptoms }\end{array}$ & $\begin{array}{l}\text { Geographical } \\
\text { Distribution }\end{array}$ & Ref. \\
\hline $\begin{array}{l}\text { Litomosoides } \\
\text { sigmodontis (aka. } \\
\text { Litomosoides carinii } \\
\text { in older literature) }\end{array}$ & $\begin{array}{l}\text { cotton rats Sigmodon hispidus } \\
\text { (experimental models: rats, } \\
\text { Mastomys, mice, jirds) }\end{array}$ & yes & $\begin{array}{l}\text { rat mites } \\
\text { (Ornithonyssus } \\
\text { bacoti) }\end{array}$ & $\begin{array}{l}\text { cotton-rat } \\
\text { filariasis }\end{array}$ & $\begin{array}{l}\text { adults in pleural cavity } \\
\text { (less commonly in } \\
\text { peritoneal cavity); mf in } \\
\text { peripheral blood }\end{array}$ & $\begin{array}{l}\text { can cause wasting and affect } \\
\text { survival; pathological changes in } \\
\text { lungs, spleen and lymphatics; } \\
\text { scattered myocarditis }\end{array}$ & $\begin{array}{l}\text { likely southeastern } \\
\text { United States, Mexico, } \\
\text { and Central America; } \\
\text { used as a model to } \\
\text { study filarial infection }\end{array}$ & {$[15-19$} \\
\hline Dirofilaria immitis & \multirow{2}{*}{$\begin{array}{l}\text { companion animals (mainly } \\
\text { dogs but also cats, ferrets) } \\
\text { and wild animals (wolves, } \\
\text { coyotes, foxes, pinnipeds, } \\
\text { raccoons, etc.); can also infect } \\
\text { humans with } D \text {. repens } \\
\text { infecting humans to a greater } \\
\text { extent than } D \text {. immitis }\end{array}$} & \multirow[t]{2}{*}{ yes } & \multirow[t]{2}{*}{ mosquitoes } & $\begin{array}{l}\text { dirofilariasis/ } \\
\text { dirofilariosis, } \\
\text { aka. heartworm } \\
\text { disease }\end{array}$ & $\begin{array}{l}\text { heart and pulmonary } \\
\text { arteries }\end{array}$ & $\begin{array}{l}\text { in dogs: cough, exercise intolerance, } \\
\text { fainting, coughing up blood, severe } \\
\text { weight loss, congestive heart failure }\end{array}$ & $\begin{array}{l}\text { most countries with } \\
\text { temperate, } \\
\text { semitropical or } \\
\text { tropical climates }\end{array}$ & {$[20,21]$} \\
\hline Dirofilaria repens & & & & $\begin{array}{l}\text { subcutaneous } \\
\text { dirofilariasis/ } \\
\text { dirofilariosis }\end{array}$ & $\begin{array}{l}\text { adults in subcutaneous } \\
\text { tissues; mf in peripheral } \\
\text { bloodstream }\end{array}$ & $\begin{array}{l}\text { mostly asymptomatic; occasionally } \\
\text { pruritus, dermal swelling, } \\
\text { subcutaneous nodules containing } \\
\text { the parasite, and ocular } \\
\text { conjunctivitis }\end{array}$ & Europe, Asia, Africa & [22] \\
\hline Loa loab & $\begin{array}{l}\text { humans (experimental } \\
\text { models: primates (e.g., } \\
\text { baboons), rodents) }\end{array}$ & no & $\begin{array}{l}\text { deerflies, genus } \\
\text { Chrysops }\end{array}$ & $\begin{array}{l}\text { loiasis, aka. } \\
\text { African eye } \\
\text { worm }\end{array}$ & connective tissue & $\begin{array}{l}\text { mostly asymptomatic, eye worm, } \\
\text { Calabar swellings, itching, tiredness, } \\
\text { muscle and joint pain, hives }\end{array}$ & $\begin{array}{l}\text { West and Central } \\
\text { Africa }\end{array}$ & [23] \\
\hline
\end{tabular}

* in specified host; LF, lymphatic filariasis; mf, microfilariae. 
With many afflicted, and even more individuals at risk of developing infections, global programs to eliminate filarial infections have been ongoing for a long period of time, from vector elimination programs initiated in 1975 to mass drug administration campaigns (MDA) with drugs that halt transmission of the infections [24]. However, significant challenges stand in the way of elimination goals, not the least of which is the lack of drugs that can effectively eliminate adult worms and cure the infections. The discovery of a bacterial endosymbiont, Wolbachia, required for viability and fecundity of adult worms causing both diseases, has provided an opportune target for drug discovery efforts. Proof-of-concept studies demonstrated the viability of this approach in human patients treated with the antibiotic doxycycline for 4 to 6 weeks, a treatment time that is unfortunately prohibitive for MDA and limited by contraindications for children and during pregnancy. Therefore, drug discovery efforts have concentrated on developing antiwolbachial therapies that are safer and effective even when given in abbreviated dosing schedules, allowing distribution to all in need of treatment. Here we detail the rationale, challenges, strategies and recent progress in developing novel antiwolbachial therapies.

\section{Filarial Worm Infection and the Antiwolbachial Approach}

\subsection{Filarial Worm Infection Biology—An Overview}

Worms that cause onchocerciasis and lymphatic filariasis are transmitted via the bites of an insect vector. In the case of onchocerciasis, O. volvulus are transmitted by black flies of the Simulium spp. that breed in fast-flowing waters of rivers. During a blood meal, infectious larvae exit the fly head and migrate into the skin of the host. Once inside the human host, the larvae develop into adults, called macrofilariae. Filarial worms have extraordinary lifespans, with $O$. volvulus worms estimated to live up to 14 years inside the human host [25]. In that time, the large female worms (up to $50 \mathrm{~cm}$ long) reside in subcutaneous nodules and release progeny called microfilariae, estimated at 16,000 per day [26], that migrate through the skin and eyes of the infected, with smaller males known to travel between nodules to fertilize the females. Black flies take up the migrating microfilariae during feeding, and these develop inside the fly into infectious larvae that can go on to infect new hosts. In addition to the nodules, symptoms of infection are associated with inflammation due to large numbers of microfilariae that migrate and die in the skin for many years. This includes intense itching and skin disease, and in extreme cases, visual impairment and even blindness. Neurological disease has also been reported.

Worms that cause lymphatic filariasis are transmitted by several mosquito species. Inside the human host the larvae develop into adults in the lymphatic system, not in subcutaneous nodules, and microfilariae shed by the macrofilariae circulate in peripheral blood, where they can be ingested by mosquitoes during a blood meal. Worms that cause lymphatic filariasis are smaller than O. volvulus (females are 4.3 to $10 \mathrm{~cm}$ long depending on the species) but like $O$. volvulus can live for long periods of time (up to 8 years [25]) during which they continue to shed large numbers of microfilariae. Many such infections are asymptomatic, but nonetheless cause damage to the lymphatics and kidneys. The visible symptoms of infection include swelling (lymphedema) of extremities and genitals (hydroceles in men), fevers, inflammation, secondary bacterial and fungal infections and acute dermato-lymphangio-adenitis attacks [27]. As the disease progresses, patients may develop elephantiasis, marked by gross swelling, hardening and thickening of the skin.

\subsection{Approved Therapies and Accompanying Challenges}

Current treatments against filarial worms (ivermectin, diethylcarbamazine (DEC), albendazole) (Table 2), alone or in combination (Table 3), are only partially effective against the long-lived macrofilariae. While the combination of DEC and albendazole has been reported to exhibit significant macrofilaricidal activity against worms that cause lymphatic filariasis $[28,29]$ the main effect of the treatments is to temporarily sterilize the adults. Thus, with additional microfilaricidal activity of ivermectin and DEC, they serve as important transmission-blocking preventive chemotherapies. In the case of onchocerciasis, the treatment can also alleviate symptoms brought on by the numerous progeny 
that circulate or migrate through the body of the infected human host and that are mostly responsible for clinical manifestations of this disease. MDA campaigns, where treatments are administered annually or bi-annually for many years (due to long reproductive lifespan of filariae) have been successfully employed to reduce disease burden and in some cases even eliminate transmission of filarial worm infections from certain regions. This includes the successful elimination of transmission of onchocerciasis from most of Central and South America with MDAs supported by the Onchocerciasis Elimination Program in the Americas (OEPA) $[30,31]$ and in Western Africa, where vector control and MDA were undertaken with the support of the Onchocerciasis Control Programme (OCP) [32]. These are great global health and philanthropic (donations of Mectizan (brand name of ivermectin) by Merck, albendazole by GSK, and DEC by Eisai) success stories. However, despite tremendous progress due to sustained MDA efforts over nearly 25 years [33], significant barriers still exist in achieving elimination goals for these widespread and disabling neglected tropical diseases.

Table 2. Antifilarial parasitic drugs.

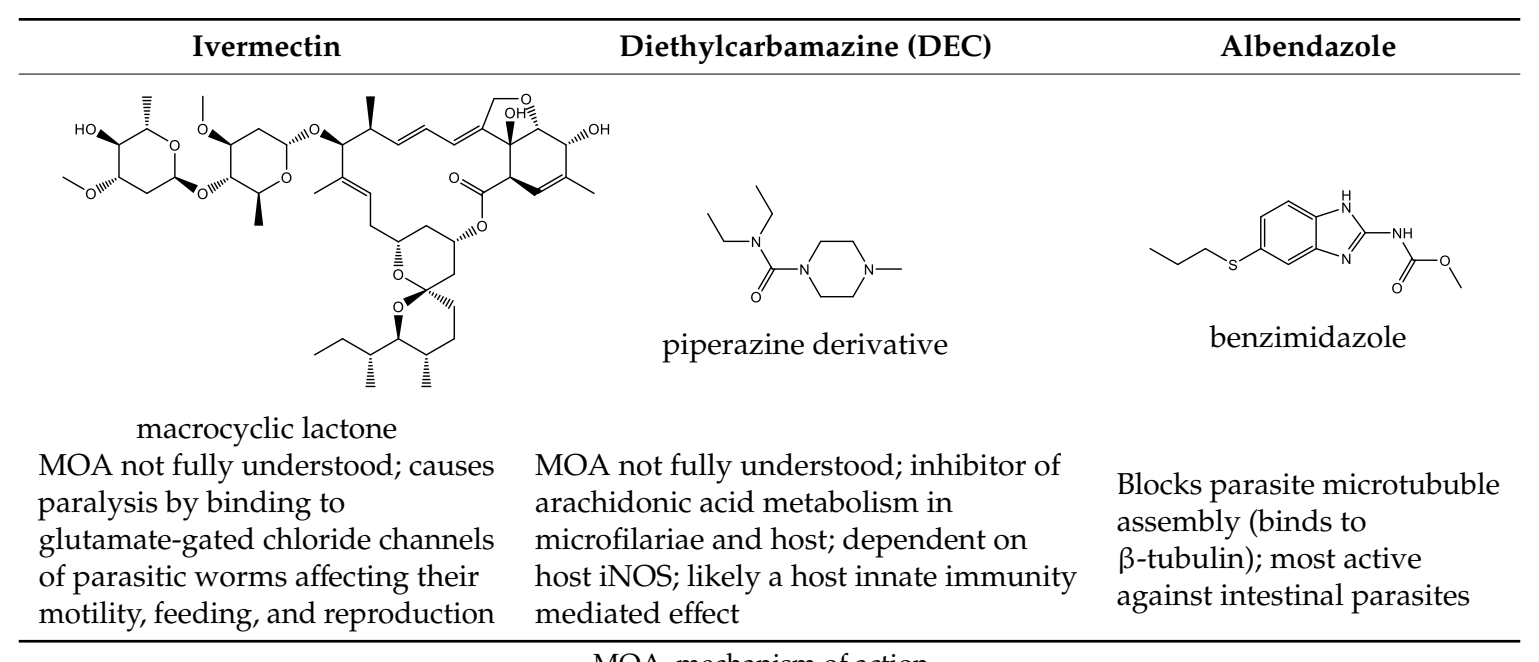

MOA, mechanism of action.

Table 3. Guidelines for treatment of filarial parasite infections through preventive chemotherapy mass drug administration campaigns.

\begin{tabular}{cccc}
\hline Disease & $\begin{array}{c}\text { Areas not Co-endemic with } \\
\text { Onchocerciasis }\end{array}$ & $\begin{array}{c}\text { Areas Co-endemic with } \\
\text { Onchocerciasis }\end{array}$ & $\begin{array}{c}\text { Areas Co-endemic } \\
\text { with Loiasis }\end{array}$ \\
\hline Onchocer-ciasis & - & $\begin{array}{c}\text { ivermectin } \\
(150-200 \mu \mathrm{g} / \mathrm{kg})\end{array}$ & $\begin{array}{c}\text { not advised; test and not } \\
\text { treat strategies investigated }\end{array}$ \\
\hline Lymphatic filariasis & $\begin{array}{c}\text { once a year DEC }(6 \mathrm{mg} / \mathrm{kg}) \\
\text { and albendazole }(400 \mathrm{mg}) ; \\
2018-2019 \text { start triple therapy } \\
\text { in select countries }\end{array}$ & $\begin{array}{c}\text { once a year ivermectin } \\
(200 \mu \mathrm{g} / \mathrm{kg}) \text { with } \\
\text { albendazole }(400 \mathrm{mg})\end{array}$ & $\begin{array}{c}\text { twice a year albendazle } \\
(400 \mathrm{mg})\end{array}$ \\
\hline Loiasis & DEC or albendazole; treatment not always recommended due to risk of SAEs; no programs \\
currently in place to control or eliminate loiasis
\end{tabular}

DEC, diethylcarbamazine citrate; SAEs, severe adverse events.

Sustained MDA coverage is complicated by geo-political issues, patient compliance (e.g., due to fear of adverse reactions to treatment), but also by the lack of macrofilaricidal activity of the drugs themselves, which requires repeated annual or bi-annual dosing for the reproductive life-span of the adult filariae (9-11 years in the case of onchocerciasis). Special barriers to treatment are also present in areas co-endemic for Loa loa (West and Central Africa), as patients infected with L. loa can develop adverse reactions following administration of microfilaricidal therapy. The adverse reactions can range between mild, moderate, to serious non-neurological and neurological reactions [34]. The neurological severe adverse events (SAEs) can cause loss of consciousness, can be fatal and are 
associated with high titers of $L$. loa microfilariae in the blood ( $>30,000$ microfilariae $/ \mathrm{mL})$. Therefore, treatments for onchocerciasis in L. loa co-endemic areas are not recommended and in the case of LF, albendazole monotherapy may be applied (Table 3); however, the overall antifilarial effectiveness (microfilariae prevalence measured over 2 weeks to 12 months after treatment) of albendazole has been questioned [35], and other approaches are being investigated. For example, the Test and Not Treat (TnT) method, enabled by development of a mobile phone microscope, advocates for identification of patients who should not receive microfilaricidal treatment due to high burdens of circulating L. loa microfilariae and the associated risk of developing SAEs. Additionally, development of an effective and safe (e.g., does not kill L. loa microfilariae) macrofilaricidal therapy that can be widely administered in resource limited settings would undeniably advance elimination of infections causing onchocerciasis (and lymphatic filariasis) in all endemic areas (Box 1).

Box 1. An abridged, working macrofilaricidal target product profile (TPP) for onchocerciasis from the Macrofilaricide Expert Group (MEG) and Macrofilaricide Drug Accelerator (MacDA) Program.

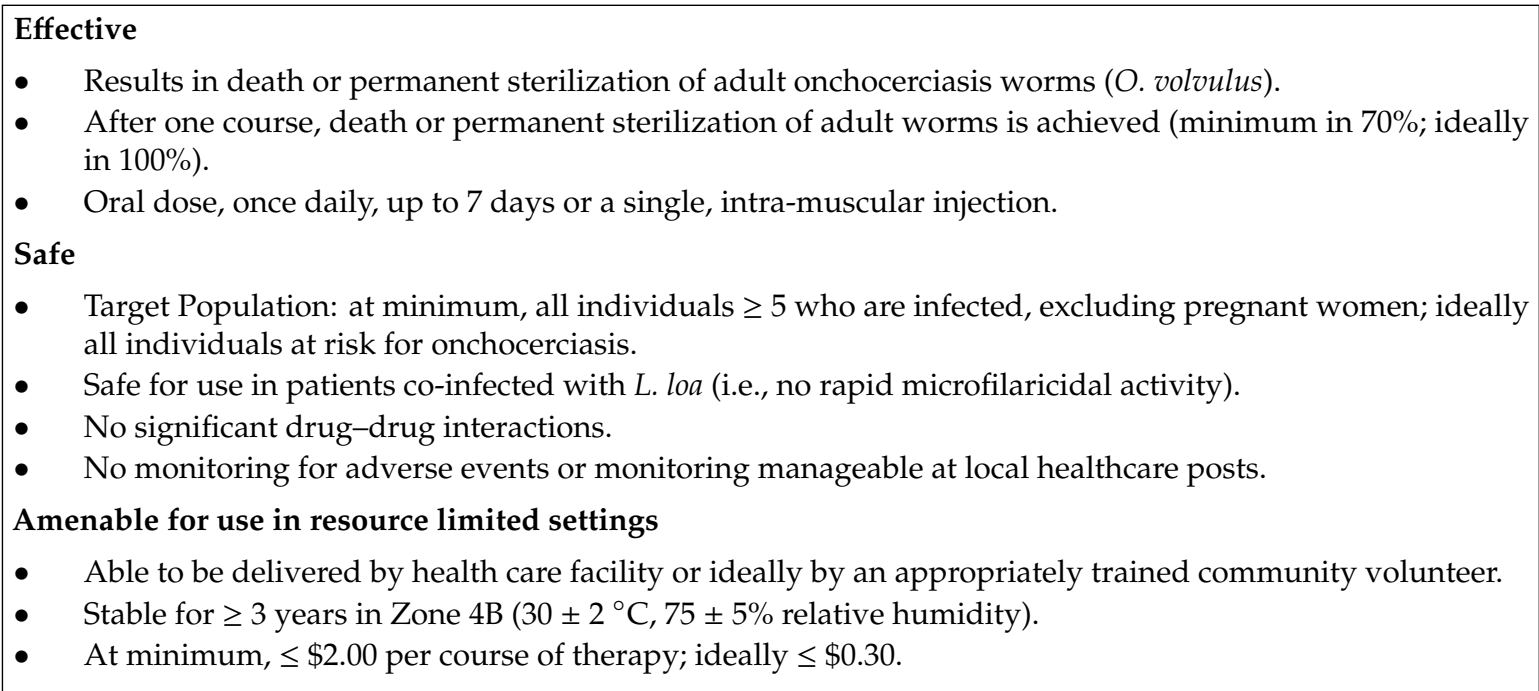

\subsection{Wolbachia, an Attractive Anti-Macrofilarial Target}

Wolbachia is a genus of gram-negative obligate intracellular bacteria related to Rickettsia. First noted in Culex pipiens mosquitoes [10] Wolbachia have subsequently been found to infect numerous invertebrate species including insects (40-65\% of insects have been estimated to be infected) and filarial nematodes [36-38]. In insects, Wolbachia are mostly maternally inherited sexual parasites known to manipulate host reproduction through cytoplasmic incompatibility, feminization and male killing, thereby increasing the proportion of infected hosts in the population. Evidence for horizontal transfer between hosts is also recognized. Wolbachia infections in mosquitoes have been observed to reduce brood size, shorten lifespans of adults, and reduce transmission of malaria, dengue, Zika and chikungunya, and are thus being exploited to control the spread of these diseases [39]. In contrast, in infected filarial nematode species Wolbachia is a maternally inherited endosymbiont required by the worms for their viability and reproduction (Tables 1 and 4). 
Table 4. Wolbachia strains of filarial nematodes of clinical relevance and ones used for antiwolbachial drug discovery.

\begin{tabular}{|c|c|c|c|c|c|}
\hline \multirow{2}{*}{ Filarial Nematode } & \multirow{2}{*}{ Significance } & \multicolumn{4}{|c|}{ Wolbachia } \\
\hline & & Strain & Super-group & Genome Size $(\mathrm{Mb})$ * & Proteins* \\
\hline Onchocerca volvulus & clinical & $w \mathrm{Ov}$ & $\mathrm{C}$ & 0.96 & 649 \\
\hline Onchocerca ochengi & advanced screen for drug and vaccine development $[3,4]$ & $w \mathrm{Oo}$ & $\mathrm{C}$ & 0.96 & 651 \\
\hline Onchocerca gutturosa & in vitro screen for drug development $[40,41]$ & $w \mathrm{Og}$ & $\mathrm{C}$ & - & - \\
\hline Dirofilaria immitis & dog heartworm (veterinary) [42] & $w$ Dim & $\mathrm{C}$ & 0.92 & 823 \\
\hline Wuchereria bancrofti & clinical & $w \mathrm{~Wb}$ & $\mathrm{D}$ & $1.06($ draft $)$ & 961 (draft) \\
\hline Brugia malayi & clinical; rodent efficacy model for drug and vaccine development [4] & $w \mathrm{Bm}$ & $\mathrm{D}$ & 1.08 & 839 \\
\hline Brugia timori & clinical & $w \mathrm{Bt}$ & $\mathrm{D}$ & - & - \\
\hline Brugia pahangi & rodent efficacy model for drug and vaccine development [17] & $w \mathrm{Bp}$ & $\mathrm{D}$ & 1.4 (draft) & 803 (draft) \\
\hline Litomosoides sigmodontis & rodent efficacy model for drug and vaccine development $[17,18,43-45]$ & $w$ Ls & $\mathrm{D}$ & \multicolumn{2}{|c|}{ Data available, but not yet published ** } \\
\hline Loa loa & clinical; microfilarial counter-screen for drug development [46] & - & - & - & - \\
\hline
\end{tabular}

${ }^{*}$ Genome size and protein number were taken from the NCBI Genomes database for Wolbachia wOv [47] (BioProject PRJEB4840), wOo [48] (BioProject PRJEA81837), $w$ Wb [49] (BioProjects PRJNA388334), wBm [50] (BioProjects PRJNA12475), and $w$ Dim [42] and $w \mathrm{Bp}[51]$ as published. ${ }^{* *}$ http://nematodes.org/genomes/litomosoides_sigmodontis/ 
Wolbachia have a somewhat controversial $[52,53]$ taxonomy, with all bacteria currently assigned to the same species, Wolbachia pipientis, but classified as belonging to distinct supergroups based on phylogenetic relationships derived from sequence analysis of ribosomal, $f t s Z$, and wsp genes. The supergroups are further divided into strains. Despite being classified as a single species, comparative genome sequencing studies have revealed that Wolbachia genomes can be highly rearranged, with many breaks in synteny and flexible gene assortments between supergroups [54]. The differing associations with their hosts (sexual parasite in insects versus obligate mutualist in filariae) are also reflected in Wolbachia genomes. Endosymbionts of Onchocerca spp. of worms and that of the dog heartworm Dirofilaria immitis belong to supergroup D and have the smallest genomes out of the currently sequenced filarial Wolbachia, just under 1 megabase $(\mathrm{Mb})$ in size, and encoding for less than a thousand proteins (Table 4). The Wolbachia of W. bancrofti, Brugia spp. and that utilized in rodent efficacy models, Litomosoides sigmodontis, belong to supergroup $\mathrm{C}$, and currently published genomes of this supergroup have similarly reduced genomes, approaching $1.1 \mathrm{Mb}$ in size. Wolbachia strains that infect fruit flies (Drosophila melanogaster) and mosquitoes (Aedes albopictus) used in drug discovery high-throughput screening efforts belong to supergroups A and B, respectively. Their genomes are approximately $1.3-1.5 \mathrm{Mb}$ in size with a larger assortment of protein coding genes (1100 and 1205, respectively), potentially reflecting the slightly more parasitic rather than mutualistic relationship with their hosts (Table 5) [50]. This still represents a marked genome reduction and gene loss compared to free-living bacteria (e.g., the E. coli K-12 genome of $4.6 \mathrm{Mb}$ encodes for nearly 4300 protein coding genes). However, the extreme genome reduction is not an unusual feature of Wolbachia, as other host-dependent obligate intracellular parasites like bacterial Chlamydia spp. [55] and Rickettsia spp. [56], and the eukaryotic pathogens microsporidia [57] that rely on the host for nutrients and a replicative environment all have highly reduced genomes. This genome reduction has been linked to the adaptation of these organisms to an obligate intracellular lifestyle and strong dependence on the host: with some metabolic functions provided by host cells, the parasites may dispense with genes involved in biosynthesis or regulatory pathways.

Despite their reduced genomes, Wolbachia have a large impact on their filarial hosts. Initial experiments showed that tetracycline treatments, used for outbreaks of staphylococcal dermatitis in jirds housed in animal facilities, could prophylactically prevent infection by B. pahangi filarial nematodes [58]. The finding that tetracycline treatment affects development and fertility of Wolbachia-containing L. sigmodontis in vivo but Wolbachia-free species are not affected by tetracycline treatment spurred further investigations into the relationship of Wolbachia with their filarial hosts and the potential for the bacteria to be used as targets for developing antifilarial therapies [59]. Wolbachia reside in the lateral hypodermal chords of filarial nematodes and in the ovaries and developing embryos within female worms. Elimination of Wolbachia with antibiotics causes sterility (an "embryostatic" effect) of female worms and slow death of the adult filariae. In general, the sterilizing effect has been attributed to widespread apoptosis immediately following Wolbachia elimination in the adult germline, the somatic cells of embryos and the microfilariae [60]. More recently, Wolbachia has been shown to be required to maintain proper development of filarial germline stem cells and for the stimulation of mitotic proliferation in the ovary [61].

Precisely why Wolbachia is required by filariae is a matter of debate and has been discussed in detail elsewhere [62]. Regardless of the precise mechanism, it has been shown in human clinical trials that doxycycline therapy at $200 \mathrm{mg} / \mathrm{kg}$ given over 4 to 6 weeks has sterilizing and macrofilaricidal effects on O. volvulus $[63,64]$, the causative agent of onchocerciasis. Sustained sterility of adult worms has clear applications for transmission blocking. Additionally, the death of $O$. volvulus macrofilariae occurred over a period of 1 to 2 years, and this gradual demise of large adult worms is considered a benefit of antiwolbachial therapy, as this, together with elimination of Wolbachia itself, may limit development of inflammation. Similar results were observed in human trials looking at efficacy of doxycycline treatments on lymphatic filariasis [19,65-68], where antiwolbachial treatments had sterilizing and macrofilaricidal effects, and via meta-analysis and other trials involving O. volvulus $[69,70]$. The 
antiwolbachial approach has also been applied to the treatment of heartworm infections in dogs, where doxycycline is part of the ideal treatment regimen. However, the long duration of doxycycline therapy in onchocerciasis and lymphatic filariasis makes it a challenge to administer. Moreover, doxycycline is contraindicated in children $\leq 8$ years of age and in pregnant women. Thus, a concerted effort has been undertaken to identify shorter, safer and more effective antiwolbachial therapies for the treatment of filarial infections. We next summarize the approaches to and findings of these antiwolbachial drug discovery efforts.

\section{Antiwolbachial Drug Discovery}

\subsection{Phenotypic Antiwolbachial High-Throughput Screening}

As obligate intracellular bacteria, Wolbachia must be cultured inside of its host's cells. As no nematode cell lines have been developed, researchers have turned to using insect cells hospitable for Wolbachia replication and amenable to growth in vitro in order to identify antiwolbachial compounds in phenotypic screens (Table 5). JW18 [71] and LDW1 [72] are cell lines derived from D. melanogaster flies infected with Wolbachia strain $w$ Mel that can be repeatedly passaged without loss of the bacteria. These lines express a fluorescent marker, the Jupiter-green fluorescent protein (GFP) fusion protein, that associates with microtubules [73]. The LDW1 cell line also expresses histone-RFP fusion localized to the nucleus of the cells [74]. The GFP and RFP tagged proteins make these lines especially attractive for high content image-based screening that relies on identification of Wolbachia using DNA staining and for cellular microbiology investigations $[71,72,75,76]$. Mosquito cell lines have also been used for Wolbachia drug discovery. One of the first insect cell lines used for antiwolbachial drug profiling, the Ae. albopictus cell line Aa23, is naturally infected with wAlb strain of Wolbachia [77]. The wAlb strain has also been transferred from Aa23 cells to the Ae. albopictus C6/36 cell line and used extensively in high-throughput screens (Table 5).

Table 5. Insect cells used for antiwolbachial high-throughput screening and features of Wolbachia strains therein.

\begin{tabular}{|c|c|c|c|c|c|c|c|}
\hline \multicolumn{3}{|c|}{ Cell Line } & \multicolumn{4}{|c|}{ Wolbachia } & \multirow{2}{*}{ References } \\
\hline Cell Line & Species & Markers & Strain & Super-group & Genome Size $(\mathrm{Mb})$ & Proteins & \\
\hline $\begin{array}{l}\mathrm{Aa} 23 \\
\mathrm{C} 6 / 36\end{array}$ & $\begin{array}{l}\text { Ae. albopictus } \\
\text { Ae. albopictus }\end{array}$ & - & $w \mathrm{Alb}$ & B & 1.48 & 1205 & $\begin{array}{l}{[77-80]} \\
{[81-90]}\end{array}$ \\
\hline $\begin{array}{l}\text { JW18 } \\
\text { LDW1 }\end{array}$ & $\begin{array}{l}\text { D. melanogaster } \\
\text { D. melanogaster }\end{array}$ & $\begin{array}{l}\text { Jupiter-GFP } \\
\text { Jupiter-GFP, } \\
\text { Histone-RFP }\end{array}$ & $w \mathrm{Mel}$ & A & 1.27 & 1100 & $\begin{array}{c}{[71,72,91]} \\
{[72,75,85,92,93]}\end{array}$ \\
\hline
\end{tabular}

A preferred detection method for high-throughput screening of chemical libraries containing thousands to hundreds of thousands of compounds is specific and relevant, inexpensive, simple, and compatible with automated liquid and plate handling equipment. To minimize costs, reduce compound consumption and increase throughput it is often desirable to miniaturize assays so that they produce good quality data providing clear distinction between positive and neutral controls (i.e., a sufficiently high signal-to-noise ratio) while using significantly less materials, e.g., by optimizing assays to be run in the lower volume 1536-well plates instead of in 384-well plates. This represents an approximate four-fold increase in throughput and proportional reductions in cost. No fluorescently tagged Wolbachia strains have been created, as no genetic tools to manipulate these bacteria have been developed, thus detection of Wolbachia within host cells in a manner amenable to HTS and miniaturization is not trivial. However, to visualize and quantify Wolbachia within host cells several approaches have been employed, including Giemsa staining [80], real-time quantitative PCR (qPCR) [77], quantitative reverse transcription PCR (qRT-PCR) [92], fluorescent nucleic acid staining (e.g., propidium iodide, 4', 6-diamidino-2-phenylindole (DAPI), and SYTO 11) [94,95], Wolbachia-specific antibody staining [77,96] and $16 \mathrm{~S}$ rRNA fluorescent in situ hybridization (FISH) $[76,97,98]$ (Table 6). 
Table 6. Wolbachia visualization and quantification methods and their utility in high-throughput screening.

\begin{tabular}{|c|c|c|c|}
\hline Quantification Method & Advantages & Disadvantages & Applied to HTS? \\
\hline Giemsa & simple, inexpensive & non-specific & no \\
\hline Propidium iodide & simple, inexpensive & non-specific & no \\
\hline DAPI & simple, inexpensive & non-specific & 384-well [71] \\
\hline Syto 11 & simple, moderately priced & non-specific & 384-well [89] \\
\hline qPCR & Wolbachia specific & complex, higher expense & 96-well $[87,88]$ \\
\hline qRT-PCR & Wolbachia specific & much more complex, higher expense & no \\
\hline Immuno-fluorescence & Wolbachia specific, simple & $\begin{array}{l}\text { higher expense, relies on limited reagent (anti-Wolbachia antibody), } \\
\text { more complex than one-reagent protocols (e.g., Syto 11) }\end{array}$ & 384-well [90] \\
\hline 16S rRNA FISH & $\begin{array}{l}\text { Wolbachia specific, simple, inexpensive } \\
\text { customizable probes }\end{array}$ & more complex than one-reagent protocols (e.g., Syto 11) & 1536-well $[92,93]$ \\
\hline
\end{tabular}

HTS, high-throughput screening. 
All of the above Wolbachia detection methods except for Giemsa, PI staining and qRT-PCR have been applied to antiwolbachial high-throughput screening, including non-specific (fluorescent nucleic acid stains) and Wolbachia-specific (qPCR, antibodies and 16S rRNA FISH) approaches (Table 6). For example, using qPCR in 96-well plate format, 2664 approved drugs, bioactive compounds and natural products (CRX; CombinatoRx, Singapore, Singapore) and 10,000 BioFocus compounds were screened in C6/36 cells to identify repurposing opportunities [88] and six structurally diverse chemotypes with in vitro antiwolbachial activity [87]. Using the JW18 cell line and DAPI staining of Wolbachia and host DNA, a high-content imaging screen of nearly 5000 compounds screened in 384-well plates with an ImageXpress Micro (Molecular Devices, Sunnyvale, CA, USA) automated imaging system equipped with a $40 \times$ objective (10 fields per well imaged) identified 40 putative hits as having antiwolbachial activity [71]. SYTO 11 staining of live C6/36 cells in 384-well plate format, imaged using a confocal $60 \times$ objective of an Operetta automated imaging system ( 3 images per field, 5 fields per well imaged) was also successfully used to screen for antiwolbachial compounds [89] and determine potency of otherwise identified hits [87].

While the DAPI and SYTO 11-based methods produced functional high-content imaging screens, the unspecific nature of these stains requires the use of high magnification objectives to discriminate effectively between Wolbachia and host DNA-derived signals, and the acquisition of multiple fields of view per well to achieve acceptable assay quality, limiting assay throughput. To overcome this limitation, Wolbachia-specific staining has since then been applied in high-content imaging assays. For example, an antibody raised against the peptidoglycan-associated lipoprotein from $B$. malayi ( $w \mathrm{BmPAL})$ was used to stain C6/36 infected cells in 384-well plate format to screen AstraZeneca's entire 1.3 million compound library, identifying 9 potential hit series [90]. While the approach relied on a specific limited reagent (anti-wBmPAL), the signals from plates were analyzed relatively quickly with a fluorescent microplate cytometer (TTP acumen Explorer eX3, Melbourn, UK) paired with Hoechst staining and a plate reader to detect host cell density (Perkin Elmer EnVision, Waltham, MA, USA), increasing throughput over previous high-content imaging approaches. Finally, 16S rRNA FISH staining optimized for high-throughput screening, which uses inexpensive and easily customizable fluorescently-labeled oligonucleotides and also results in a Wolbachia-specific signal, allowed us to screen over 300,000 compounds from Calibr's focused diversity and bioactive libraries, identifying 288 potent and selective hits, including known drugs and novel chemical entities such as the quinazoline heterocycles [92]. This was initially done in 384-well plate format, and upon further miniaturization in 1536-well plate format using a CX5 CellInsight Cellomics high-content imaging instrument (Thermo Fisher Scientific, Waltham, MA, United States) with a 10× magnification objective, requiring only a single field of view per well, thereby significantly increasing throughput.

\subsection{Validation of Antiwolbachial Compounds Identified in Vitro Screens}

The large phenotypic screening efforts outlined above have yielded much novel chemical matter with potential antiwolbachial activity. More obvious in vitro hits, such as analogs of already validated antibiotics, have been successfully advanced for in vivo proof-of-concept testing (e.g., minocycline, a derivative of doxycycline [99]). Analysis of chemical structures to censor compounds that are obviously intractable for development is a standard procedure in drug discovery and serves to narrow the focus to candidates without clear liabilities. However, validation of the remaining promising in vitro hits against filarial Wolbachia continues to represent a bottleneck in the antiwolbachial discovery process. As discussed above, there are marked differences between Wolbachia genomes and lifestyles of strains from insect and filarial nematodes, and it is possible that compounds identified in insect-cell screens will have strain-specific activity. The phenotypic screening approach and reliance of Wolbachia on host cells for survival and a replicative environment also makes it possible that compounds identified will have host-specific activity. And, fully-developed adult worms, the target of antiwolbachial therapy, present a significant permeability barrier, and may block entry, metabolize, or excrete active compounds. Many "straight-off-the-screening-deck" compounds have also not been chemically optimized to maintain 
proper exposures and metabolic stability in in vivo models. It is no surprise therefore, that many of the promising potent antiwolbachial compounds identified in insect cell-based screens show disappointing activity against Wolbachia in filarial nematodes in vitro or in vivo.

Another layer of complexity is that the macrofilaricidal effect on adult worms following elimination of Wolbachia takes a long time to be observed, 1-2 years in the case of $O$. volvulus in human patients [63]. Thus, the primary readout of validated compounds even in in vivo models is usually elimination of Wolbachia, which, if insufficient, is reversible, as is the embryostatic effect it imparts. It is unclear what is the precise threshold of elimination required for a sustained effect (estimated to be $>90 \%$ in patients based on doxycycline clinical trials [4]), but incomplete elimination of the bacteria can lead to eventual repopulation of worm tissues (e.g., as seen with a 14-day $40 \mathrm{mg} / \mathrm{kg}$ bid (bis in die, twice a day) doxycycline treatment in the jird/L. sigmodontis model of infection [86]). Moreover, the specific elimination thresholds that must be achieved in disparate preclinical models to translate to clinical efficacy are also topics of deliberation, with clear answers likely to emerge as more compounds vetted in these systems enter clinical trials.

Not counting the bovine O. ochengi model [3], the most reliable and physiologically relevant validation tools are the in vivo rodent filarial infection models that have been developed to study filarial diseases and where sustained Wolbachia elimination, and in some cases even the embryostatic effects, can be observed following compound treatment $[4,17,45,92,100]$. However, these models require large amounts of chemical matter, can take weeks to months in order to establish and perform, and compounds not optimized to achieve high enough exposures in rodents may give needlessly discouraging results. In addition to the significant time and resources required, the ethical challenges presented by excessive use of such models as secondary validation screens are also an obstacle: a typical high-throughput screen may identify hundreds of attractive hits. The timelines involved, also preclude rapid turnaround for efficient medicinal chemistry optimization cycles. Therefore, other faster and less-resource intensive methods of validating activity of compounds against filarial Wolbachia have been developed and employed.

Validation of antiwolbachial compounds in filarial nematodes outside of in vivo models faces unique challenges. Wolbachia distribution between different developmental stages and even different worms of the same sex and age is variable. Additionally, without more complicated assay systems such as provision of feeder cell monolayers [40,101], parasitic worms can be maintained outside of their host (ex vivo) for limited amounts of time. Nonetheless, validation against filarial Wolbachia ex vivo has been performed using microfilariae and adult male and female worms, using several quantification methods and filarial species.

The most abundant filarial life stage are the microfilariae, which are easily accessible in large quantities from infected animals and may serve as surrogates for adult filariae. However, microfilariae contain significantly less Wolbachia then adult worms, do not have developed reproductive systems where Wolbachia resides, and are arguably much more permeable and susceptible to compound treatments. Male worms have also been used to validate antiwolbachial compound activities, as they are smaller than females and more convenient to work with (e.g., in a sister species of the human parasite $O$. volvulus that infects cattle, Onchocerca ochengi [3], adult females are $25 \mathrm{~cm}$ and males are $3 \mathrm{~cm}$ long [43]). Yet, the males may also represent a lower threshold for compound validation as they do not contain Wolbachia in their reproductive tracts, and due to this fact and the relative size difference contain significantly less Wolbachia compared to females. Importantly, clearance of Wolbachia from all tissues, including the reproductive tract, may be important for compound efficacy in vivo, and long-term sterility and eventual death of the filariae. For example, Wolbachia in the ovaries of O. ochengi are more resistant to rifampin antibiotic treatment in cattle than Wolbachia in hypodermal chords of either male or female worms [102] and this population, if not eliminated, may eventually recover in the female reproductive tract following cessation of treatment. Similarly, we observed that the Wolbachia population found in the reproductive tract of B. pahangi adult female worms is more resistant than the population found in the hypodermis to an ex vivo treatment with doxycycline and a 
novel series of antiwolbachial quinazolines, as analyzed through imaging of Wolbachia in ovaries with $16 \mathrm{~S}$ rRNA FISH and qRT-PCR performed on whole worms and specific worm tissues [92]. Conversely, immunohistochemical observations in D. immitis following doxycycline treatment suggested complete clearance of Wolbachia from ovaries of worms and a marked decrease in number of Wolbachia in the hypodermis [96]. These observations are difficult to reconcile with the available data, but their incongruity may be due to the timing of treatments and observations. While it has been established that during development Wolbachia from the hypodermis infects the female reproductive tract [98,103], the replication of Wolbachia within the female gonad and the dynamics of Wolbachia populations within worms in response to specific compound treatments are yet to be defined. In fact, it is possible that nearly complete elimination of Wolbachia from the hypodermis is needed for efficacy, and it is correlated to elimination in the ovaries in the above examples.

Regardless, while validating Wolbachia elimination in filariae by any method is a significant first step in selecting attractive small molecules, being able to differentiate compound activities and select ones with the highest chance of success (rapid and total elimination of Wolbachia) is advantageous for efficient prioritization and development of superior chemical matter. Translation of validation results to in vivo efficacy has been variable, and likely not always related to absolute compound potency, but no consistent analysis comparing these methods has been undertaken thus far. Yet, in our experience the quantification of Wolbachia specifically near the distal tip cell of the ovaries of adult female B. pahangi worms following a 3-day treatment ex vivo (Figure 1) paired with optimization of exposures in vivo led to selection of exquisitely potent antiwolbachial compounds capable of eliminating $>99 \%$ of Wolbachia from L. sigmodonits worms in vivo after a single dose [92]. Whether this indicates that elimination of Wolbachia found in the ovaries of filariae is relevant for sustained antiwolbachial effect, represents a proxy for efficient Wolbachia elimination throughout the worm, or if this population is particularly insensitive to some or all antiwolbachial treatments remains to be fully elucidated.
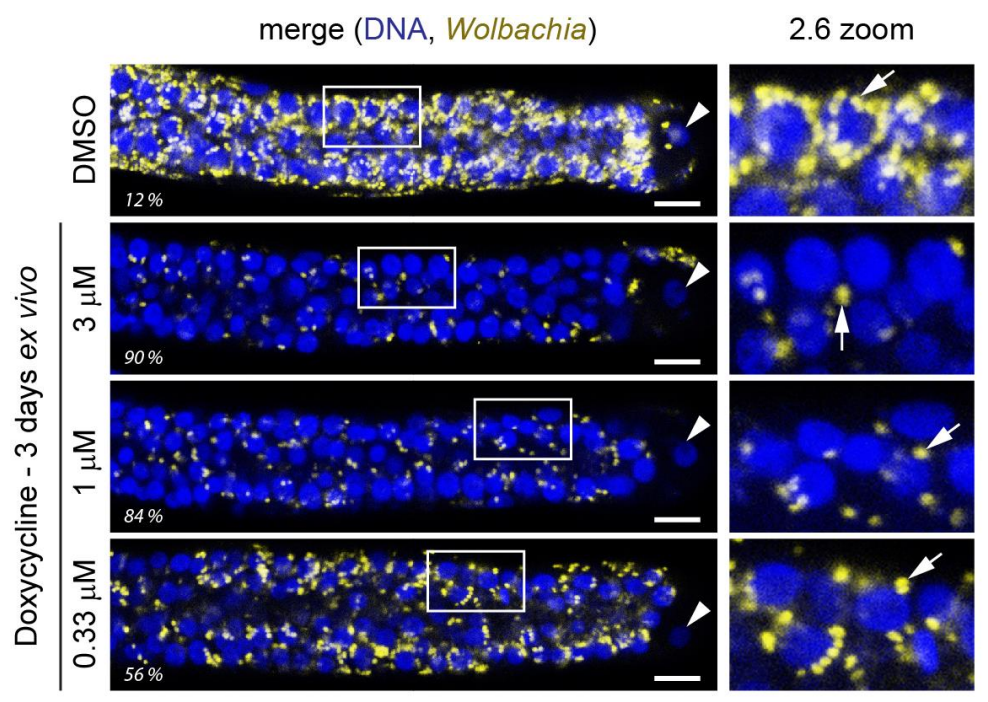

Figure 1. An ex vivo assay allows for rapid quantification of Wolbachia elimination in adult female worm ovaries near the distal tip cell due to compound treatment. Here, effects of a 3-day doxycycline treatment on female adult B. pahangi worms is shown. Worms are extracted from jirds and treated in 24-well plates, with one worm per well and usually 2 worms per treatment condition (with total of four ovaries analyzed). Worms are fixed, their ovaries dissected out, and stained with Wolbachia-specific $16 \mathrm{~S}$ rRNA fluorescent in situ hybridization (FISH) (yellow). The stained ovaries are mounted on slides with DAPI-containing mounting medium to stain DNA (blue) and their distal ends imaged using a confocal microscope. The Wolbachia-specific 16S rRNA FISH is quantified by high content image analysis and normalized to DMSO control samples (percent elimination indicated here for each displayed ovary). Panels on the right are the enlarged sections demarcated with a white box in the ovary images. Wolbachia $w \mathrm{Bp}$ is indicated with arrows and the distal tip cell nucleus with an arrowhead. Scale bar $=10 \mu \mathrm{m}$. 


\section{Promising Antiwolbachial Candidates}

The cumulative effect of screening and validation activities has been the discovery and development of several promising antiwolbachial candidates. This includes novel and yet unoptimized chemical series, more advanced developed molecules, repurposing opportunities and alternative dosing regimens. The most advanced programs have molecules that are in or have undergone human trials, hoping to prove both safety and efficacy of these promising macrofilaricidal therapies.

\subsection{Novel Chemical Series}

Perhaps some of the most intriguing leads in antiwolbachial drug discovery are small molecules with novel chemical structures. More than a dozen such series have been identified in screening efforts and published to date and represent a viable starting point for further medicinal chemistry optimization (Figure 2). Identified in phenotypic whole cell screens, the targets responsible for antiwolbachial activity of these novel compounds are currently unknown. However, focused chemical optimization efforts on the thienopyrimidine series [87] and the quinazoline series [92] have led to generation of molecules with excellent efficacy and properties: AWZ1066S and quinazolines CBR417 and CBR490 (Table 7).

(a)

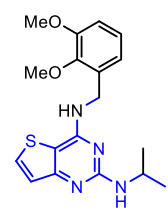

1. Thienopyrimidine

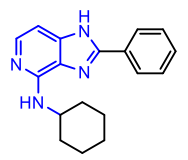

2. Imidazo[4,5-c]pyridine<smiles>CS(=O)(=O)c1ccc(-c2ccc3c(c2)N(Cc2ccccc2)C(=O)COC3)cc1</smiles>

3. Oxazepinone

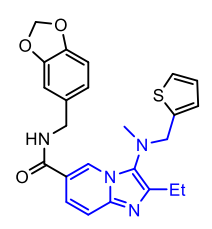

4. Imidazo[1,2-a]pyridine

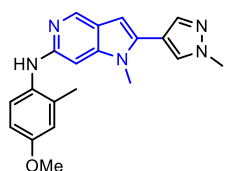

5. Pyrrolopyridine

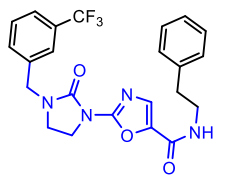

6. Oxazole imidazolidino $\vdots$ (b)

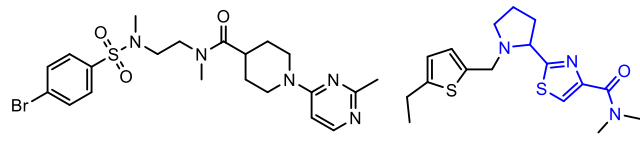

$1 \mathrm{~A}$ (cluster 1)

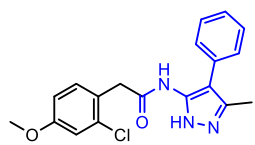

2A (cluster 2)

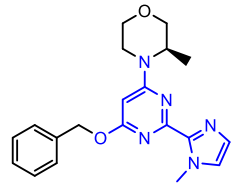

3A (cluster 3)

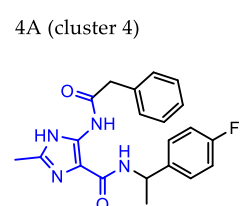

$5 \mathrm{~A}$ (cluster 5)

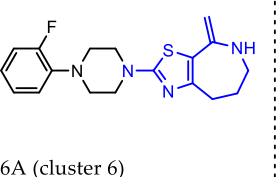

(c)

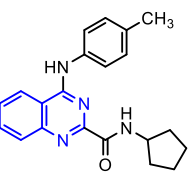

Quinazoline

Figure 2. Representative structures of published antiwolbachial hit series identified in insect cell-based high-throughput screens with the cores of each series highlighted in blue. Series identified in screens using: (a) C6/36 insect cells with wAlb quantified using $\mathrm{QPCR}$ and Syto 11 high content imaging assay [87]; (b) C6/36 insect cells with $w A$ Alb quantified using immunofluorescence (wBmPAL antibody staining) [90]; (c) LDW1 insect cells with $w$ Mel quantified using 16S rRNA FISH [92]. 
Table 7. Advanced novel small molecules optimized for antiwolbachial efficacy.

\begin{tabular}{llll}
\hline & AWZ1066S [86] & CBR490 [92] & CBR417 [92] \\
\hline Series & azaquinazoline & quinazoline (methylpyridine)
\end{tabular}

\subsubsection{AWZ1066S}

Chemical optimization of the thienopyrimidine series [87] identified in high-throughput screening led to the generation of AWZ1066, a compound with a quinazoline scaffold and increased efficacy against both insect and filarial Wolbachia. In the process of medicinal chemistry optimization over 300 analogs were synthesized and assessed for antiwolbachial activity and drug metabolism/pharmacokinetic (DMPK) properties [86]. AWZ1066 has two enantiomers, AWZ1066S and AWZ1066R, with AWZ1066S (Table 7) demonstrating slightly superior antiwolbachial activity. Assays used to assess activity of the compound during medicinal chemistry optimization included the 7-day in vitro C6/36 insect cells high content screening assay (SYTO 11) and a 6-day B. malayi microfilarial in vitro assay (qPCR), where both AWZ1066 enantiomers show activity superior to the doxycycline control. The good DMPK properties and potency of AWZ1066 translated well to in vivo models of filarial infection. When dosed for 7 days at $100 \mathrm{mg} / \mathrm{kg}$ bid, AWZ1066S eliminated $98 \%$ of Wolbachia from B. malayi adult female worms in SCID mice. The elimination was even greater, $>99 \%$, when AWZ1066S was similarly dosed for 14 days. Importantly, in the L. sigmodontis jird model of infection, a 7-day dosing regimen of $50 \mathrm{mg} / \mathrm{kg}$ bid eliminated $>99 \%$ of Wolbachia in the adult female worms measured at 18 weeks post treatment, indicating elimination of bacteria to low enough titers to block repopulation of worm tissues after conclusion of treatment. This treatment also led to sterilization and gradual depletion of microfilariae from infected jird circulation. Together with favorable safety profiles, these data support AWZ1066S as an attractive novel antiwolbachial.

\subsubsection{Quinazolines CBR417 and CBR490}

During the high-throughput screening using LDW1 insect cells and a high-content imaging assay relying on $16 \mathrm{~S}$ rRNA FISH to detect Wolbachia, many novel small molecules and known drugs were identified as potent against $w \mathrm{Mel}$ strain of Wolbachia. However, novel compounds with a quinazoline scaffold had the additional advantage of being active against filarial Wolbachia found in adult B. pahangi ovaries in a 3-day ex vivo assay at levels superior to the doxycycline control. Focusing on DMPK properties and potency against filarial Wolbachia found in adult female B. pahangi ovaries, medicinal chemistry optimization of the quinazoline series generated quinazolines CBR417 and CBR490 (Table 7), with improved potencies compared to doxycycline in both the in vitro and ex vivo assays, excellent exposure and safety profiles. This translated to unparalleled in vivo efficacy: in the mouse model of L. sigmodontis infection a single dose of either quinazoline at $200 \mathrm{mg} / \mathrm{kg}$ caused a $>99 \%$ elimination of Wolbachia from adult female worms. More modest doses given over longer periods of time caused an equivalent Wolbachia reduction (e.g., 2 doses of $100 \mathrm{mg} / \mathrm{kg}$ given once per week). Additionally, a less advanced quinazoline analog from the series, CBR715, showed strong efficacy in adult B. malayi 
females and O. ochengi males in SCID mouse models of infection, causing $>99 \%$ Wolbachia elimination when dosed at $50 \mathrm{mg} / \mathrm{kg}$ bid for 7 days. Dose range finding studies would need to be completed in these models to determine whether further dose and time reductions of treatment would be possible with CBR417 and CBR490. Nonetheless, these preliminary data suggest that the series has excellent potential to be developed as significantly abbreviated antiwolbachial therapies. Finally, the conspicuous structural similarity of CBR417 and CBR490 to the independently-developed AWZ1066S may suggest a related mode of action for these novel molecules. However, quinazoline heterocycles are present in many biologically active compounds found throughout drug discovery. Therefore, whether these molecules have the same or similar targets relevant for their antiwolbachial effect remains to be determined.

\subsection{Repurposing of Known Drugs and Alternative Dosing Regimens}

\subsubsection{Minocycline}

Minocycline is a tetracycline class antibiotic related to doxycycline with antiwolbachial activity observed in insect cells and in filarial nematodes [40,88,92]. In filarial nematodes in vitro [40], ex vivo [92] and in vivo [88], minocycline activity is superior compared to equivalent doses of doxycycline Pharmacodynamic modeling also suggests the superiority of minocycline over doxycycline when dosed proportionally [99]. A recent human pilot trial compared the efficacy of a 4-week or 3-week $200 \mathrm{mg} /$ day doxycycline to that of a 3-week $200 \mathrm{mg} /$ day minocycline therapy in O. volvulus infected individuals in Ghana [104]. While the findings were not conclusive due to the small size of the study, a trend of increased potency of minocycline was observed compared to the 3-week $200 \mathrm{mg} /$ day doxycycline, but with the 4-week doxycycline treatment ultimately showing superior efficacy. Therefore, more comprehensive studies are required to assess the possibility of minoncycline as a faster-acting antiwolbachial therapy. Methacycline, an older tetracycline antibiotic, was also shown to have superior activity compared to doxycycline in vivo [88] but has not garnered the same attention as minocycline likely because of its lower absorption and lipophilicity compared to either doxycycline or minocycline [105].

\subsubsection{High Dose Rifampicin}

Rifampicin is a clinically approved antibiotic used in the treatment of tuberculosis that inhibits RNA synthesis by binding to and inhibiting the DNA-dependent RNA polymerase of bacteria. The long-standing interest in rifampicin as an antiwolbachial [80] has resulted in many studies of its activity and it's potential as a macrofilaricide has been thoroughly explored $[40,77,106]$. Rifampicin is very potent in vitro against Wolbachia in insect cells and demonstrates in vivo efficacy in rodent animal models when dosed appropriately. Additionally, it is less toxic than doxycycline and can be administered to children. However, in in vivo models and clinical trials using standard dose of rifampicin approved for tuberculosis treatment $(10 \mathrm{mg} / \mathrm{kg})$, rifampicin failed to show the anticipated efficacy. For example, in a clinical trial its ability to clear Wolbachia from O. volvulus when given at $10 \mathrm{mg} / \mathrm{kg}$ over 2 or 4 weeks to infected patients was shown to be inferior to that of a 6-week $200 \mathrm{mg} / \mathrm{kg}$ doxycycline treatment [107]. Additionally, in W. bancrofti patients, a 2-week long combination treatment of $200 \mathrm{mg} / \mathrm{kg}$ doxycycline plus $10 \mathrm{mg} / \mathrm{kg}$ rifampicin was also inferior to a 4-week $200 \mathrm{mg} / \mathrm{kg}$ doxycycline treatment [65]. Similar results were observed in cattle infected with O. ochengi [102]. However, recent investigations into tolerability of higher dose of rifampicin for tuberculosis treatments combined with lower costs of synthesis, prompted further investigations into efficacious dose modeling for rifampicin as an antiwolbachial [108]. Results from in vivo dose escalation studies and drug exposure modeling simulations suggest that a minimum dose of $30-40 \mathrm{mg} / \mathrm{kg}$ in humans could achieve rifampicin exposures conducive to elimination of Wolbachia and a macrofilaricidal effect. Based on in vivo efficacy studies in SCID mouse models of B. malayi and O. ochengi infection, the high dose rifampicin treatment would likely need to be administered for at least one week to treat lymphatic filariasis and two weeks 
to treat onchocerciasis. The shortened dosing regimens have an added advantage in that they may be less likely to cause development of antibiotic resistance in tuberculosis patients.

\subsubsection{Corallopyronin A}

Corallopyronin A is a natural product of Corallococcus coralloides B035 and a noncompetitive inhibitor of bacterial DNA-dependent RNA polymerase. It inhibits the RNA polymerase via a mechanism different from rifampicin and has low efficacy against Mycobacterium spp., suggesting that unlike rifampicin, it could be administered without the concern over development of antibiotic resistance in tuberculosis patients, inciting investigations into its antiwolbachial activity $[109,110]$. In fact, corallopyronin A was shown to be effective against Wolbachia in vitro and in vivo but due to limitation in the amount of corallopyronin A that was available at the time the in vivo studies were conducted, superiority to doxycycline has thus far not been determined. Nonetheless, corallopyronin A may be an attractive antiwolbachial alone or in combination, especially when considering the development of antibiotic resistance due to antiwolbachial antibiotic treatment in patients co-infected with Mycobacterium tuberculosis.

\subsubsection{DNA Gyrase Inhibitors: Fluoroquinolones and Aminocoumarins}

Fluoroquinolones possess variable antiwolbachial activity. Ciprofloxacin, initially tested in Aa23 $w$ AlbB-infected cells showed no [80] or moderate effect (MIC $=2-4 \mu \mathrm{g} / \mathrm{mL}$ ) [77] on Wolbachia titers. Ofloxacin and levofloxacin that were also tested in vitro showed similarly moderate effects [77]. Initial L. sigmodontis in vivo studies with ciprofloxacin also resulted in disappointing results [111]. Further work led to re-discovery of fluoroquinolones as potential antiwolbachials with ciprofloxacin, moxifloxacin and sparfloxacin demonstrating activities in vitro in C6/36 insect cells [88]. In the same study, ciprofloxacin and moxifloxacin also showed antiwolbachial effects in an adult O. gutturosa in vitro assay, and ciprofloxacin and sparfloxacin showed reduction in Wolbachia loads and reductions in L. sigmodontis worm length in vivo when dosed one day following initiation of filarial infection for 14 days. More recently, other fluoroquinolones were identified as having activity against $w$ Mel Wolbachia in LDW1 cells (delafloxacin, finafloxacin, nadifloxacin, sitafloxacin) with $\mathrm{EC}_{50}$ values ranging between $243 \mathrm{nM}$ and $808 \mathrm{nM}$ [92]. However, they were not active against $w B p$ in adult $B$. pahangi females in a 3-day ex vivo assay, causing at most a $25 \%$ reduction in Wolbachia in worm ovaries following a $1 \mu \mathrm{M}$ treatment. Interestingly, other antibiotics targeting the bacterial DNA gyrase, the aminocoumarins, showed similar patterns of activity in the same study. Aminocoumarins were exquisitely potent against $w \mathrm{Mel}$ in insect cells (coumermycin $\mathrm{EC}_{50}=1.5 \mathrm{nM}$ ) but were not able to clear Wolbachia effectively from ovaries of $B$. pahangi ( $44 \%$ wBp elimination at $1 \mu \mathrm{M}$ coumermycin). This may reflect the lower potency of both fluoroquinolones and aminocoumarins against filarial Wolbachia, their slower mode of action, or insufficient accumulation in worm tissues. Therefore, identification or synthesis of more effective analogs would likely be required for these compounds to be deployed as macrofilaricidal therapies.

\subsubsection{Kirromycins}

Kirromycin, also known as mocimycin, is an elfamcyin class antibiotic with a narrow spectrum of activity. Kirromycin inhibits protein synthesis by interacting with the prokaryotic elongation factor $\mathrm{Tu}$ (EF-Tu), trapping EF-Tu on the ribosome and preventing the next round of elongation [112]. Recently, kirromycin B was identified as a potent antiwolbachial in a screen of the Natural Products Library (NPL) constructed by the The Natural Products Library Initiative at the Scripps Research Institute. The NPL consists of crude microbial extracts, fractions generated by medium-pressure liquid chromatography (MPLC), and pure natural products [93]. Kirromcyin B showed excellent antiwolbachial activity in vitro in Drosophila insect cells $\left(\mathrm{IC}_{50}=0.58 \mathrm{nM}\right)$ and ex vivo in B. pahangi adult worm ovaries ( $90 \%$ Wolbachia $w$ Bp elimination from ovaries of worms treated for 3 days with $1 \mu \mathrm{M}$ kirromycin B). Investigation of the kirromycin B-producing strain Streptomyces sp. CB00686 led to identification of two additional congeners, kirromycin and kirromycin $\mathrm{C}$ as having similar antiwolbachial activities 
in vitro ( $\mathrm{IC}_{50} \mathrm{~s}$ of $0.25 \mathrm{nM}$ and $1.08 \mathrm{nM}$, respectively) and slightly lower activities ex vivo (65\% and $67 \%$ elimination at $1 \mu \mathrm{M}$, respectively). Interestingly, similar levels of activity were observed ex vivo at lower concentrations for all three compounds $(0.33$ and $0.11 \mu \mathrm{M})$ as at $1 \mu \mathrm{M}$, suggesting perhaps a potent but bacteriostatic mode of action (a similarly "flat", albeit less-potent, antiwolbachial activity profile was observed for Tylosin A [92]). While these data are very promising, investigation in in vivo models of filarial infection are required to determine the utility of kirromycins and other elfamycins as antiwolbachial candidates for treatment of filarial worm infections.

\subsection{Chemically-Optimized Antibiotics}

\subsubsection{Boron-Pleuromutilin, AN11251}

Benzoxaboroles have been found to impart favorable properties to existing drug scaffolds and boron-containing chemistry has been successfully used by Anacor Pharmaceuticals (recently acquired by Pfeizer) to generate potent molecules for several infectious disease indications. In addition to FDA-approved anti-fungal therapy, this includes the modification of pleuromutilin class of antibiotics, shown to have antiwolbachial activity in vitro [85]. Pleuromutilins are bacteriostatic protein synthesis inhibitors that act by direct binding to the peptidyl-transfer center of the bacterial ribosome. Pleuromutilin itself does not possess strong antiwolbachial activity ( $w$ AlbB EC $50>1 \mu \mathrm{M}$ ), with other pleuromutilins more potent against Wolbachia in insect cells [85,92]. For example, valnemulin in LDW1 cells has $\mathrm{EC}_{50} \mathrm{~s}$ ranging between $6.1-30 \mathrm{nM}$ and is active against Wolbachia in B. pahangi ovaries as assessed in a short 3-day ex vivo assay where $1 \mu \mathrm{M}$ valnemulin treatment causes $67 \% w \mathrm{Bp}$ elimination from ovaries, activity that is similar to that of doxycycline [85,92]. Using boron-containing chemistry to impart more favorable properties to pleuromutilins, boron-pleuromutilin series optimization led to the generation of AN11251 (Figure 3(a)), which was exquisitely potent in vitro against C6/36 Wolbachia-containing insect cells ( $w \mathrm{Alb} \mathrm{EC}_{50}=15 \mathrm{nM}$ ). The activity of AN11251 was confirmed in vivo in the L. sigmodontis mouse model of infection, where oral administration of AN11251 at $50 \mathrm{mg} / \mathrm{kg}$ bid for 14 days caused a $>99 \%$ elimination of Wolbachia from adult female worms. However, dosing could not be reduced sufficiently to meet the $<7$-day dosing target. Therefore, further investigations to determine if AN11251 dosing regimen can be abbreviated by combination therapy are underway.

(a)

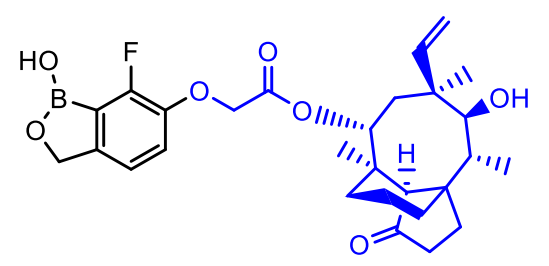

AN11251, a boron-pleuromutilin (b)

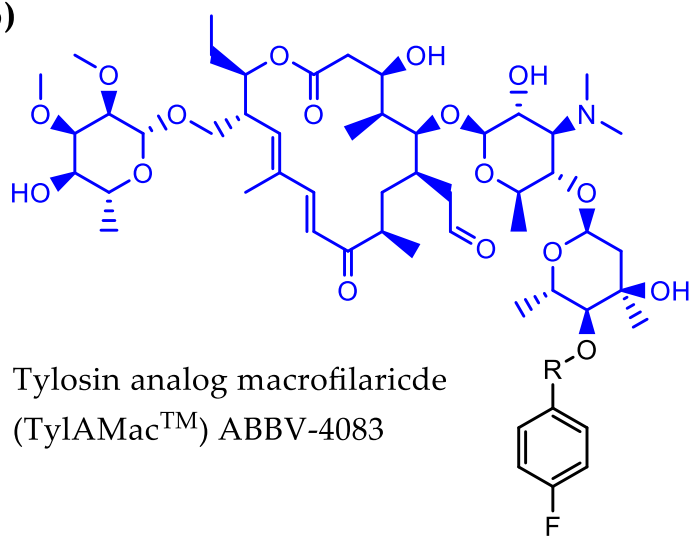

Figure 3. Structures of AN11251 (a) and the tylosin core of ABBV-4083 (TylAMac) (b). The antibiotic core of each molecule is colored blue.

\subsubsection{Tylosin Analog ABBV-4083}

Tylosin is a macrolide antibiotic and an animal food additive used in agriculture. Like pleuromutilins, tylosins are bacteriostatic and inhibit protein synthesis by binding to the bacterial ribosome, specifically in the peptide exit tunnel of the bacterial 50S ribosomal subunit [113]. Activity against Wolbachia discovered in insect cells prompted the chemistry optimization program led by AbbVie 
together with the A-WOL Consortium to increase the oral bioavailability of tylosin and generate a tylosin analog microfilaricide (TylAMac ${ }^{\mathrm{TM}}$ ) $[114,115]$. The generated lead molecule ABBV-4083 (Figure 3b) showed a potent in vitro antiwolbachial activity in insect cells $\left(\mathrm{EC}_{50}=0.019 \mathrm{nM}\right)$ that was nearly 1500-fold more potent than that of Tylosin A [114]. ABBV-4083 also demonstrated in vivo efficacy and superiority over doxycycline in a jird model of infection, where a 14-day treatment with $150 \mathrm{mg} / \mathrm{kg}$ PO ABBV-4083 resulted in a $99.91 \%$ Wolbachia elimination as measured 16 weeks post-treatment initiation, blocked embryogenesis and a complete clearance of circulating microfilariae [114]. ABBV-4083 performed well in preclinical safety studies and showed further efficacy in additional in vivo models of filarial infection [115]. Furthermore, based on its relatively low anti-L. loa $\mathrm{mf}$ in vitro activity $\left(\mathrm{IC}_{50}=23.3 \mu \mathrm{M}\right)$ it was predicted to be safe to administer to patients co-infected with L. loa [115]. In 2018 in partnership with the Liverpool School of Tropical Medicine and the Drugs for Neglected Diseases initiative (DNDi), Abbvie successfully completed a phase I clinical trial assessing the safety and tolerability of ABBV-4083. The encouraging findings from this trial support advancement of ABBV-4083 to phase II clinical trials (https://www.dndi.org/diseases-projects/portfolio/abbv-4083/).

\subsection{Combination Therapies and Target-Based Screening}

What are some of the other directions for future antiwolbachial macrofilaricide development? In addition to continued optimization and preclinical development of novel small molecule candidates using recently validated workflows, profiling of efficacy of combination therapies is an attractive strategy. The recognized challenge of developing effective fast-acting compounds may be overcome by pairing antiwolbachials with synergistic activities or with other antifilarial compounds such as albendazole to deliver superior treatments. This approach is not always successful: pairing of doxycycline with rifampicin does not improve outcomes and may even lead to inferior results. However, examples highlighting the potential of this strategy include in vivo studies pairing albendazole with minocycline or rifampicin [116], and other combination antibiotic treatments (e.g., rifapentine and moxifloxacin) [106], all showing superior efficacy of combinations versus monotherapies. A small pilot trial has also demonstrated that combining albendazole with doxycycline may provide a shorter treatment course [104]. The success of albendazole as a synergistic partner with other antiwolbachial therapies may stem from its action as a filarial microtubule inhibitor with indirect effects on Wolbachia. Regardless, albendazole's purported antifilarial effect and extensive use in patients infected with filaria (including those with loiasis) makes albendazole an attractive partner for antiwolbachial therapy.

High-throughput and more focused screening that identified antibiotics with known mode of action has also indirectly identified druggable Wolbachia targets that it shares with other bacterial pathogens. This includes the ribosome (tetracyclines, pleuromutilins, macrolides), the DNA-dependent RNA polymerase (rifamycins, corallopyronin A), the DNA gyrase (fluoroquinolones, aminocoumarins), lipoprotein signal peptidase II (LspA) (globomycin) [84] and finally the peptide deformylase, as a number of peptide deformylase inhibitors have recently been identified as having antiwolbachial activity [92]. However, target-based screening has not enjoyed the same success and prevalence as phenotypic screens in antiwolbachial drug discovery largely due to lack of validated druggable Wolbachia targets outside this standard antibacterial repertoire. The few efforts made in this arena include biochemical screens identifying inhibitors of the B. malayi FtsZ GTPase [117] and inhibitors of heme pathway targeting the Wolbachia $\delta$-aminolevulinic acid dehydratase (wALAD) $[118,119]$. Yet as targets of novel validated antiwolbachial compounds are identified, target-based screening may take a more prominent role in antiwolbachial drug discovery efforts in the future.

\section{Perspectives for the Future of Antiwolbachial Drug Discovery}

Over the last two decades, significant strides were made towards the discovery of antiwolbachial therapies for filarial worm infections. Through the support of charitable organizations such as the Bill and Melinda Gates Foundation, the Global Health Innovative Technology Fund (GHIT), DND $i$ and other funding bodies, the organized and targeted efforts of the A-WOL Consortium [120] led by the 
Liverpool School of Tropical Medicine in collaboration with other academic and industrial partners (Abbvie, Anacor, AstraZeneca, Eisai, New England Biolabs, University of Buea, University of Bonn, University of Liverpool and others), many novel chemical structures with in vitro antiwolbachial activity have been identified and even advanced through clinical studies. This is largely owing to the successful high-throughput screening and validation frameworks that have been developed and yielded a wealth of results in the last five years. However, compared with other neglected tropical diseases, the clinical development pipeline for macrofilaricides remains scarcely populated. Following favorable phase I results, the tylosin analog ABBV-4083 will likely progress into Phase II clinical trials. Clearly, much depends on the success of this clinical candidate and its ability to contribute to filarial disease elimination goals. Securing the significant funding required for pre-clinical and clinical development of novel small molecules may be both challenging yet instrumental in the event of failure or uncovered liabilities of candidates in advanced studies. The lessons learned over the last five years of intensive antiwolbachial drug discovery should prove vital in the event of unfavorable results.

Funding: The global health unit of Calibr is supported by the Bill \& Melinda Gates Foundation (OPP1107194).

Acknowledgments: We are grateful to the members and leadership of the Macrofilaricide Drug Accelerator, especially Ken Duncan, Richard Elliott, and Scott Mills.

Conflicts of Interest: The authors declare no conflict of interest. The funders had no role in the writing of the manuscript.

\section{References}

1. Taylor, M.J.; Hoerauf, A.; Bockarie, M. Lymphatic filariasis and onchocerciasis. Lancet 2010, 376, 1175-1185. [CrossRef]

2. Hotterbeekx, A.; Namale Ssonko, V.; Oyet, W.; Lakwo, T.; Idro, R. Neurological manifestations in Onchocerca volvulus infection: A review. Brain Res. Bull. 2019, 145, 39-44. [CrossRef] [PubMed]

3. Makepeace, B.L.; Tanya, V.N. 25 Years of the Onchocerca ochengi Model. Trends Parasitol. 2016, 32, 966-978. [CrossRef] [PubMed]

4. Halliday, A.; Guimaraes, A.F.; Tyrer, H.E.; Metuge, H.M.; Patrick, C.N.; Arnaud, K.O.; Kwenti, T.D.; Forsbrook, G.; Steven, A.; Cook, D.; et al. A murine macrofilaricide pre-clinical screening model for onchocerciasis and lymphatic filariasis. Parasites Vectors 2014, 7, 472. [CrossRef] [PubMed]

5. WHO. Global programme to eliminate lymphatic filariasis: Progress report, 2015. Wkly. Epidemiol. Rec. 2016, 91, 441-455.

6. Muslim, A.; Fong, M.Y.; Mahmud, R.; Sivanandam, S. Vector and reservoir host of a case of human Brugia pahangi infection in Selangor, peninsular Malaysia. Trop. Biomed. 2013, 30, 727-730. [PubMed]

7. Tan, L.H.; Fong, M.Y.; Mahmud, R.; Muslim, A.; Lau, Y.L.; Kamarulzaman, A. Zoonotic Brugia pahangi filariasis in a suburbia of Kuala Lumpur City, Malaysia. Parasitol. Int. 2011, 60, 111-113. [CrossRef] [PubMed]

8. McNulty, S.N.; Mitreva, M.; Weil, G.J.; Fischer, P.U. Inter and intra-specific diversity of parasites that cause lymphatic filariasis. Infect. Genet. Evol. 2013, 14, 137-146. [CrossRef]

9. Nutman, T.B. Insights into the pathogenesis of disease in human lymphatic filariasis. Lymphat. Res. Biol. 2013, 11, 144-148. [CrossRef]

10. Hertig, M.; Wolbach, S.B. Studies on Rickettsia-Like Micro-Organisms in Insects. J. Med. Res. 1924, 44, 329.

11. Lima, N.F.; Veggiani Aybar, C.A.; Dantur Juri, M.J.; Ferreira, M.U. Mansonella ozzardi: A neglected New World filarial nematode. Pathog. Glob. Health 2016, 110, 97-107. [CrossRef] [PubMed]

12. Casiraghi, M.; Favia, G.; Cancrini, G.; Bartoloni, A.; Bandi, C. Molecular identification of Wolbachia from the filarial nematode Mansonella ozzardi. Parasitol. Res. 2001, 87, 417-420. [CrossRef] [PubMed]

13. Ta-Tang, T.H.; Crainey, J.L.; Post, R.J.; Luz, S.L.; Rubio, J.M. Mansonellosis: Current perspectives. Res. Rep. Trop. Med. 2018, 9, 9-24. [CrossRef] [PubMed]

14. Keiser, P.B.; Coulibaly, Y.; Kubofcik, J.; Diallo, A.A.; Klion, A.D.; Traore, S.F.; Nutman, T.B. Molecular identification of Wolbachia from the filarial nematode Mansonella perstans. Mol. Biochem. Parasitol. 2008, 160, 123-128. [CrossRef] [PubMed] 
15. King, D.F. Some developments in techniques for the study of the rodent filarial parasite Litomosoides carinii. II. A quantitative method for the culture of the mite Ornithonyssus bacoti and for the routine transmission of Litomosoides carinii to Praomys (Mastomys) natalensis. Ann. Trop. Med. Parasitol. 1968, 62, 469-477. [CrossRef] [PubMed]

16. Pringle, G.; King, D.F. Some developments in techniques for the study of the rodent filarial parasite Litomosoides carinii. I. A preliminary comparison of the host effciency of the multimammate rat, Praomys (Mastomys) natalensis, with that of the cotton rat, Sigmodon hispidus. Ann. Trop. Med. Parasitol. 1968, 62, 462-468. [CrossRef]

17. Morris, C.P.; Evans, H.; Larsen, S.E.; Mitre, E. A comprehensive, model-based review of vaccine and repeat infection trials for filariasis. Clin. Microbiol. Rev. 2013, 26, 381-421. [CrossRef]

18. Hawking, F.; Sewell, P. The maintenance of a filarial infection (Litomosoides carinii) for chemotherapeutic investigations. Br. J. Pharmacol. Chemother. 1948, 3, 285-296. [CrossRef]

19. Turner, J.D.; Mand, S.; Debrah, A.Y.; Muehlfeld, J.; Pfarr, K.; McGarry, H.F.; Adjei, O.; Taylor, M.J.; Hoerauf, A. A randomized, double-blind clinical trial of a 3-week course of doxycycline plus albendazole and ivermectin for the treatment of Wuchereria bancrofti infection. Clin. Infect. Dis. 2006, 42, 1081-1089. [CrossRef]

20. Simon, F.; Siles-Lucas, M.; Morchon, R.; Gonzalez-Miguel, J.; Mellado, I.; Carreton, E.; Montoya-Alonso, J.A. Human and animal dirofilariasis: The emergence of a zoonotic mosaic. Clin. Microbiol. Rev. 2012, 25, 507-544. [CrossRef]

21. Alho, A.M.; Marcelino, I.; Colella, V.; Flanagan, C.; Silva, N.; Correia, J.J.; Latrofa, M.S.; Otranto, D.; Madeira de Carvalho, L. Dirofilaria immitis in pinnipeds and a new host record. Parasites Vectors 2017, 10, 142. [CrossRef] [PubMed]

22. Genchi, C.; Kramer, L. Subcutaneous dirofilariosis (Dirofilaria repens): An infection spreading throughout the old world. Parasites Vectors 2017, 10, 517. [CrossRef] [PubMed]

23. Whittaker, C.; Walker, M.; Pion, S.D.S.; Chesnais, C.B.; Boussinesq, M.; Basanez, M.G. The Population Biology and Transmission Dynamics of Loa loa. Trends Parasitol. 2018, 34, 335-350. [CrossRef] [PubMed]

24. Remme, J.H.F.; Feenstra, P.; Lever, P.R.; Medici, A.C.; Morel, C.M.; Noma, M.; Ramaiah, K.D.; Richards, F.; Seketeli, A.; Schmunis, G.; et al. Tropical Diseases Targeted for Elimination: Chagas Disease, Lymphatic Filariasis, Onchocerciasis, and Leprosy. In Disease Control Priorities in Developing Countries, 2nd ed.; Jamison, D.T., Breman, J.G., Measham, A.R., Alleyne, G., Claeson, M., Evans, D.B., Jha, P., Mills, A., Musgrove, P., Eds.; World Bank and Oxford University Press: Washington, DC, USA, 2006.

25. Gems, D. Longevity and ageing in parasitic and free-living nematodes. Biogerontology 2000, 1, $289-307$. [CrossRef] [PubMed]

26. Mawson, A.R.; WaKabongo, M. Onchocerciasis-associated morbidity: Hypothesis. Trans. R. Soc. Trop. Med. Hyg. 2002, 96, 541-542. [CrossRef]

27. Shenoy, R.K. Clinical and pathological aspects of filarial lymphedema and its management. Korean J. Parasitol. 2008, 46, 119-125. [CrossRef]

28. Kar, S.K.; Dwibedi, B.; Das, B.K.; Agrawala, B.K.; Ramachandran, C.P.; Horton, J. Lymphatic pathology in asymptomatic and symptomatic children with Wuchereria bancrofti infection in children from Odisha, India and its reversal with DEC and albendazole treatment. PLoS Negl. Trop. Dis. 2017, 11, e0005631. [CrossRef] [PubMed]

29. Kar, S.K.; Dwibedi, B.; Kerketa, A.S.; Maharana, A.; Panda, S.S.; Mohanty, P.C.; Horton, J.; Ramachandran, C.P. A randomized controlled trial of increased dose and frequency of albendazole with standard dose DEC for treatment of Wuchereria bancrofti microfilaremics in Odisha, India. PLoS Negl. Trop. Dis. 2015, 9, e0003583. [CrossRef] [PubMed]

30. Program Coordinating, C.; Staff, O. Guide to detecting a potential recrudescence of onchocerciasis during the posttreatment surveillance period: The American paradigm. Res. Rep. Trop. Med. 2012, 3, 21-33. [CrossRef]

31. Sauerbrey, M. The Onchocerciasis Elimination Program for the Americas (OEPA). Ann. Trop. Med. Parasitol. 2008, 102 (Suppl. 1), 25-29. [CrossRef]

32. Dadzie, Y.; Neira, M.; Hopkins, D. Final report of the Conference on the eradicability of Onchocerciasis. Filaria J. 2003, 2, 2. [CrossRef] [PubMed]

33. Kuesel, A.C. Research for new drugs for elimination of onchocerciasis in Africa. Int. J. Parasitol. Drugs Drug Resist. 2016, 6, 272-286. [CrossRef] [PubMed] 
34. Boussinesq, M.; Gardon, J.; Gardon-Wendel, N.; Chippaux, J.P. Clinical picture, epidemiology and outcome of Loa-associated serious adverse events related to mass ivermectin treatment of onchocerciasis in Cameroon. Filaria J. 2003, 2 (Suppl. 1). [CrossRef] [PubMed]

35. Macfarlane, C.L.; Budhathoki, S.S.; Johnson, S.; Richardson, M.; Garner, P. Albendazole alone or in combination with microfilaricidal drugs for lymphatic filariasis. Cochrane Database Syst. Rev. 2019, 1, CD003753. [CrossRef] [PubMed]

36. McLaren, D.J.; Worms, M.J.; Laurence, B.R.; Simpson, M.G. Micro-organisms in filarial larvae (Nematoda). Trans. R. Soc. Trop. Med. Hyg. 1975, 69, 509-514. [CrossRef]

37. Kozek, W.J. Transovarially-transmitted intracellular microorganisms in adult and larval stages of Brugia malayi. J. Parasitol. 1977, 63, 992-1000. [CrossRef] [PubMed]

38. Kozek, W.J.; Marroquin, H.F. Intracytoplasmic bacteria in Onchocerca volvulus. Am. J. Trop. Med. Hyg. 1977, 26, 663-678. [CrossRef] [PubMed]

39. Niang, E.H.A.; Bassene, H.; Fenollar, F.; Mediannikov, O. Biological Control of Mosquito-Borne Diseases: The Potential of Wolbachia-Based Interventions in an IVM Framework. J. Trop. Med. 2018, 2018, 1470459. [CrossRef]

40. Townson, S.; Tagboto, S.; McGarry, H.F.; Egerton, G.L.; Taylor, M.J. Onchocerca parasites and Wolbachia endosymbionts: Evaluation of a spectrum of antibiotic types for activity against Onchocerca gutturosa in vitro. Filaria J. 2006, 5, 4. [CrossRef]

41. Townson, S. The development of a laboratory model for onchocerciasis using Onchocerca gutturosa: In vitro culture, collagenase effects, drug studies and cryopreservation. Trop. Med. Parasitol. 1988, 39 (Suppl. 4), 475-479.

42. Godel, C.; Kumar, S.; Koutsovoulos, G.; Ludin, P.; Nilsson, D.; Comandatore, F.; Wrobel, N.; Thompson, M.; Schmid, C.D.; Goto, S.; et al. The genome of the heartworm, Dirofilaria immitis, reveals drug and vaccine targets. FASEB J. 2012, 26, 4650-4661. [CrossRef]

43. Allen, J.E.; Adjei, O.; Bain, O.; Hoerauf, A.; Hoffmann, W.H.; Makepeace, B.L.; Schulz-Key, H.; Tanya, V.N.; Trees, A.J.; Wanji, S.; et al. Of mice, cattle, and humans: The immunology and treatment of river blindness. PLoS Negl. Trop. Dis. 2008, 2, e217. [CrossRef]

44. Fulton, A.; Babayan, S.A.; Taylor, M.D. Use of the Litomosoides sigmodontis Infection Model of Filariasis to Study Type 2 Immunity. Methods Mol. Biol. 2018, 1799, 11-26. [CrossRef]

45. Hubner, M.P.; Torrero, M.N.; McCall, J.W.; Mitre, E. Litomosoides sigmodontis: A simple method to infect mice with L3 larvae obtained from the pleural space of recently infected jirds (Meriones unguiculatus). Exp. Parasitol. 2009, 123, 95-98. [CrossRef]

46. Pionnier, N.P.; Sjoberg, H.; Chunda, V.C.; Fombad, F.F.; Chounna, P.W.; Njouendou, A.J.; Metuge, H.M.; Ndzeshang, B.L.; Gandjui, N.V.; Akumtoh, D.N.; et al. Mouse models of Loa loa. Nat. Commun. 2019, 10, 1429. [CrossRef]

47. Cotton, J.A.; Bennuru, S.; Grote, A.; Harsha, B.; Tracey, A.; Beech, R.; Doyle, S.R.; Dunn, M.; Hotopp, J.C.; Holroyd, N.; et al. The genome of Onchocerca volvulus, agent of river blindness. Nat. Microbiol. 2016, 2, 16216. [CrossRef]

48. Darby, A.C.; Armstrong, S.D.; Bah, G.S.; Kaur, G.; Hughes, M.A.; Kay, S.M.; Koldkjaer, P.; Rainbow, L.; Radford, A.D.; Blaxter, M.L.; et al. Analysis of gene expression from the Wolbachia genome of a filarial nematode supports both metabolic and defensive roles within the symbiosis. Genome Res. 2012, 22, 2467-2477. [CrossRef]

49. Chung, M.; Small, S.T.; Serre, D.; Zimmerman, P.A.; Dunning Hotopp, J.C. Draft genome sequence of the Wolbachia endosymbiont of Wuchereria bancrofti wWb. Pathog. Dis. 2017, 75. [CrossRef]

50. Foster, J.; Ganatra, M.; Kamal, I.; Ware, J.; Makarova, K.; Ivanova, N.; Bhattacharyya, A.; Kapatral, V.; Kumar, S.; Posfai, J.; et al. The Wolbachia genome of Brugia malayi: Endosymbiont evolution within a human pathogenic nematode. PLoS Biol. 2005, 3, e121. [CrossRef]

51. Lau, Y.L.; Lee, W.C.; Xia, J.; Zhang, G.; Razali, R.; Anwar, A.; Fong, M.Y. Draft genome of Brugia pahangi: High similarity between B. pahangi and B. malayi. Parasites Vectors 2015, 8, 451. [CrossRef]

52. Pfarr, K.; Foster, J.; Slatko, B.; Hoerauf, A.; Eisen, J.A. On the taxonomic status of the intracellular bacterium Wolbachia pipientis: Should this species name include the intracellular bacteria of filarial nematodes? Int. J. Syst. Evol Microbiol. 2007, 57, 1677-1678. [CrossRef] 
53. Lo, N.; Paraskevopoulos, C.; Bourtzis, K.; O’Neill, S.L.; Werren, J.H.; Bordenstein, S.R.; Bandi, C. Taxonomic status of the intracellular bacterium Wolbachia pipientis. Int. J. Syst. Evol. Microbiol. 2007, 57, 654-657. [CrossRef]

54. Klasson, L.; Walker, T.; Sebaihia, M.; Sanders, M.J.; Quail, M.A.; Lord, A.; Sanders, S.; Earl, J.; O’Neill, S.L.; Thomson, N.; et al. Genome evolution of Wolbachia strain wPip from the Culex pipiens group. Mol. Biol. Evol. 2008, 25, 1877-1887. [CrossRef]

55. Nunes, A.; Gomes, J.P. Evolution, phylogeny, and molecular epidemiology of Chlamydia. Infect. Genet. Evol. 2014, 23, 49-64. [CrossRef]

56. Renesto, P.; Ogata, H.; Audic, S.; Claverie, J.M.; Raoult, D. Some lessons from Rickettsia genomics. FEMS Microbiol. Rev. 2005, 29, 99-117. [CrossRef]

57. Katinka, M.D.; Duprat, S.; Cornillot, E.; Metenier, G.; Thomarat, F.; Prensier, G.; Barbe, V.; Peyretaillade, E.; Brottier, P.; Wincker, P.; et al. Genome sequence and gene compaction of the eukaryote parasite Encephalitozoon cuniculi. Nature 2001, 414, 450-453. [CrossRef]

58. Bosshardt, S.C.; McCall, J.W.; Coleman, S.U.; Jones, K.L.; Petit, T.A.; Klei, T.R. Prophylactic activity of tetracycline against Brugia pahangi infection in jirds (Meriones unguiculatus). J. Parasitol. 1993, 79, 775-777. [CrossRef]

59. Hoerauf, A.; Nissen-Pahle, K.; Schmetz, C.; Henkle-Duhrsen, K.; Blaxter, M.L.; Buttner, D.W.; Gallin, M.Y.; Al-Qaoud, K.M.; Lucius, R.; Fleischer, B. Tetracycline therapy targets intracellular bacteria in the filarial nematode Litomosoides sigmodontis and results in filarial infertility. J. Clin. Investig. 1999, 103, 11-18. [CrossRef]

60. Landmann, F.; Voronin, D.; Sullivan, W.; Taylor, M.J. Anti-filarial activity of antibiotic therapy is due to extensive apoptosis after Wolbachia depletion from filarial nematodes. PLoS Pathog. 2011, 7, e1002351. [CrossRef]

61. Foray, V.; Perez-Jimenez, M.M.; Fattouh, N.; Landmann, F. Wolbachia Control Stem Cell Behavior and Stimulate Germline Proliferation in Filarial Nematodes. Dev. Cell 2018, 45, 198-211. [CrossRef]

62. Slatko, B.E.; Luck, A.N.; Dobson, S.L.; Foster, J.M. Wolbachia endosymbionts and human disease control. Mol. Biochem. Parasitol. 2014, 195, 88-95. [CrossRef]

63. Hoerauf, A.; Specht, S.; Buttner, M.; Pfarr, K.; Mand, S.; Fimmers, R.; Marfo-Debrekyei, Y.; Konadu, P.; Debrah, A.Y.; Bandi, C.; et al. Wolbachia endobacteria depletion by doxycycline as antifilarial therapy has macrofilaricidal activity in onchocerciasis: A randomized placebo-controlled study. Med. Microbiol. Immunol. 2008, 197, 295-311. [CrossRef]

64. Turner, J.D.; Tendongfor, N.; Esum, M.; Johnston, K.L.; Langley, R.S.; Ford, L.; Faragher, B.; Specht, S.; Mand, S.; Hoerauf, A.; et al. Macrofilaricidal activity after doxycycline only treatment of Onchocerca volvulus in an area of Loa loa co-endemicity: A randomized controlled trial. PLoS Negl. Trop. Dis. 2010, 4, e660. [CrossRef]

65. Debrah, A.Y.; Mand, S.; Marfo-Debrekyei, Y.; Batsa, L.; Albers, A.; Specht, S.; Klarmann, U.; Pfarr, K.; Adjei, O.; Hoerauf, A. Macrofilaricidal Activity in Wuchereria bancrofti after 2 Weeks Treatment with a Combination of Rifampicin plus Doxycycline. J. Parasitol. Res. 2011, 2011, 201617. [CrossRef]

66. Debrah, A.Y.; Mand, S.; Marfo-Debrekyei, Y.; Batsa, L.; Pfarr, K.; Buttner, M.; Adjei, O.; Buttner, D.; Hoerauf, A. Macrofilaricidal effect of 4 weeks of treatment with doxycycline on Wuchereria bancrofti. Trop. Med. Int. Health 2007, 12, 1433-1441. [CrossRef]

67. Taylor, M.J.; Makunde, W.H.; McGarry, H.F.; Turner, J.D.; Mand, S.; Hoerauf, A. Macrofilaricidal activity after doxycycline treatment of Wuchereria bancrofti: A double-blind, randomised placebo-controlled trial. Lancet 2005, 365, 2116-2121. [CrossRef]

68. Hoerauf, A.; Mand, S.; Fischer, K.; Kruppa, T.; Marfo-Debrekyei, Y.; Debrah, A.Y.; Pfarr, K.M.; Adjei, O.; Buttner, D.W. Doxycycline as a novel strategy against bancroftian filariasis-depletion of Wolbachia endosymbionts from Wuchereria bancrofti and stop of microfilaria production. Med. Microbiol. Immunol. 2003, 192, 211-216. [CrossRef]

69. Debrah, A.Y.; Specht, S.; Klarmann-Schulz, U.; Batsa, L.; Mand, S.; Marfo-Debrekyei, Y.; Fimmers, R.; Dubben, B.; Kwarteng, A.; Osei-Atweneboana, M.; et al. Doxycycline Leads to Sterility and Enhanced Killing of Female Onchocerca volvulus Worms in an Area With Persistent Microfilaridermia After Repeated Ivermectin Treatment: A Randomized, Placebo-Controlled, Double-Blind Trial. Clin. Infect. Dis. 2015, 61, 517-526. [CrossRef] 
70. Walker, M.; Specht, S.; Churcher, T.S.; Hoerauf, A.; Taylor, M.J.; Basanez, M.G. Therapeutic efficacy and macrofilaricidal activity of doxycycline for the treatment of river blindness. Clin. Infect. Dis. 2015, 60, 1199-1207. [CrossRef]

71. Serbus, L.R.; Landmann, F.; Bray, W.M.; White, P.M.; Ruybal, J.; Lokey, R.S.; Debec, A.; Sullivan, W. A cell-based screen reveals that the albendazole metabolite, albendazole sulfone, targets Wolbachia. PLoS Pathog. 2012, 8, e1002922. [CrossRef]

72. White, P.M.; Pietri, J.E.; Debec, A.; Russell, S.; Patel, B.; Sullivan, W. Mechanisms of Horizontal Cell-to-Cell Transfer of Wolbachia spp. in Drosophila melanogaster. Appl. Environ. Microbiol. 2017, 83. [CrossRef]

73. Karpova, N.; Bobinnec, Y.; Fouix, S.; Huitorel, P.; Debec, A. Jupiter, a new Drosophila protein associated with microtubules. Cell Motil. Cytoskeleton 2006, 63, 301-312. [CrossRef]

74. Emery, G.; Hutterer, A.; Berdnik, D.; Mayer, B.; Wirtz-Peitz, F.; Gaitan, M.G.; Knoblich, J.A. Asymmetric Rab 11 endosomes regulate delta recycling and specify cell fate in the Drosophila nervous system. Cell 2005, 122, 763-773. [CrossRef]

75. White, P.M.; Serbus, L.R.; Debec, A.; Codina, A.; Bray, W.; Guichet, A.; Lokey, R.S.; Sullivan, W. Reliance of Wolbachia on High Rates of Host Proteolysis Revealed by a Genome-Wide RNAi Screen of Drosophila Cells. Genetics 2017, 205, 1473-1488. [CrossRef]

76. Grobler, Y.; Yun, C.Y.; Kahler, D.J.; Bergman, C.M.; Lee, H.; Oliver, B.; Lehmann, R. Whole genome screen reveals a novel relationship between Wolbachia levels and Drosophila host translation. PLoS Pathog. 2018, 14, e1007445. [CrossRef]

77. Fenollar, F.; Maurin, M.; Raoult, D. Wolbachia pipientis growth kinetics and susceptibilities to 13 antibiotics determined by immunofluorescence staining and real-time PCR. Antimicrob. Agents Chemother. 2003, 47, 1665-1671. [CrossRef]

78. Sinha, A.; Li, Z.; Sun, L.; Carlow, C.K.S. Complete Genome Sequence of the Wolbachia wAlbB Endosymbiont of Aedes albopictus. Genome Biol. Evol. 2019. [CrossRef]

79. O'Neill, S.L.; Pettigrew, M.M.; Sinkins, S.P.; Braig, H.R.; Andreadis, T.G.; Tesh, R.B. In vitro cultivation of Wolbachia pipientis in an Aedes albopictus cell line. Insect. Mol. Biol. 1997, 6, 33-39. [CrossRef]

80. Hermans, P.G.; Hart, C.A.; Trees, A.J. In vitro activity of antimicrobial agents against the endosymbiont Wolbachia pipientis. J. Antimicrob. Chemother. 2001, 47, 659-663. [CrossRef]

81. Fenollar, F.; La Scola, B.; Inokuma, H.; Dumler, J.S.; Taylor, M.J.; Raoult, D. Culture and phenotypic characterization of a Wolbachia pipientis isolate. J. Clin. Microbiol. 2003, 41, 5434-5441. [CrossRef]

82. Igarashi, A. Isolation of a Singh's Aedes albopictus cell clone sensitive to Dengue and Chikungunya viruses. J. Gen. Virol. 1978, 40, 531-544. [CrossRef]

83. Turner, J.D.; Langley, R.S.; Johnston, K.L.; Egerton, G.; Wanji, S.; Taylor, M.J. Wolbachia endosymbiotic bacteria of Brugia malayi mediate macrophage tolerance to TLR- and CD40-specific stimuli in a MyD88/TLR2-dependent manner. J. Immunol. 2006, 177, 1240-1249. [CrossRef]

84. Johnston, K.L.; Wu, B.; Guimaraes, A.; Ford, L.; Slatko, B.E.; Taylor, M.J. Lipoprotein biosynthesis as a target for anti-Wolbachia treatment of filarial nematodes. Parasites Vectors 2010, 3, 99. [CrossRef]

85. Jacobs, R.T.; Lunde, C.S.; Freund, Y.R.; Hernandez, V.; Li, X.; Xia, Y.; Carter, D.S.; Berry, P.; Halladay, J.; Rock, F.; et al. Boron-Pleuromutilins as Anti-Wolbachia Agents with Potential for Treatment of Onchocerciasis and Lymphatic Filariasis. J. Med. Chem. 2019. [CrossRef]

86. Hong, W.D.; Benayoud, F.; Nixon, G.L.; Ford, L.; Johnston, K.L.; Clare, R.H.; Cassidy, A.; Cook, D.A.N.; Siu, A.; Shiotani, M.; et al. AWZ1066S, a highly specific anti-Wolbachia drug candidate for a short-course treatment of filariasis. Proc. Natl. Acad. Sci. USA 2019, 116, 1414-1419. [CrossRef]

87. Johnston, K.L.; Cook, D.A.N.; Berry, N.G.; David Hong, W.; Clare, R.H.; Goddard, M.; Ford, L.; Nixon, G.L.; O'Neill, P.M.; Ward, S.A.; et al. Identification and prioritization of novel anti-Wolbachia chemotypes from screening a 10,000-compound diversity library. Sci. Adv. 2017, 3, eaao1551. [CrossRef]

88. Johnston, K.L.; Ford, L.; Umareddy, I.; Townson, S.; Specht, S.; Pfarr, K.; Hoerauf, A.; Altmeyer, R.; Taylor, M.J. Repurposing of approved drugs from the human pharmacopoeia to target Wolbachia endosymbionts of onchocerciasis and lymphatic filariasis. Int. J. Parasitol. Drugs Drug Resist. 2014, 4, 278-286. [CrossRef]

89. Clare, R.H.; Cook, D.A.; Johnston, K.L.; Ford, L.; Ward, S.A.; Taylor, M.J. Development and validation of a high-throughput anti-Wolbachia whole-cell screen: A route to macrofilaricidal drugs against onchocerciasis and lymphatic filariasis. J. Biomol. Screen. 2015, 20, 64-69. [CrossRef] 
90. Clare, R.H.; Bardelle, C.; Harper, P.; Hong, W.D.; Borjesson, U.; Johnston, K.L.; Collier, M.; Myhill, L.; Cassidy, A.; Plant, D.; et al. Industrial scale high-throughput screening delivers multiple fast acting macrofilaricides. Nat. Commun. 2019, 10, 11. [CrossRef]

91. Wu, M.; Sun, L.V.; Vamathevan, J.; Riegler, M.; Deboy, R.; Brownlie, J.C.; McGraw, E.A.; Martin, W.; Esser, C.; Ahmadinejad, N.; et al. Phylogenomics of the reproductive parasite Wolbachia pipientis wMel: A streamlined genome overrun by mobile genetic elements. PLoS Biol. 2004, 2, e69. [CrossRef]

92. Bakowski, M.A.; Shiroodi, R.K.; Liu, R.; Olejniczak, J.; Yang, B.; Gagaring, K.; Guo, H.; White, P.M.; Chappell, L.; Debec, A.; et al. Discovery of short-course antiwolbachial quinazolines for elimination of filarial worm infections. Sci. Transl. Med. 2019, 11. [CrossRef]

93. Xu, Z.; Fang, S.M.; Bakowski, M.A.; Rateb, M.E.; Yang, D.; Zhu, X.; Huang, Y.; Zhao, L.X.; Jiang, Y.; Duan, Y.; et al. Discovery of Kirromycins with Anti-Wolbachia Activity from Streptomyces sp. CB00686. ACS Chem. Biol. 2019. [CrossRef]

94. Casper-Lindley, C.; Kimura, S.; Saxton, D.S.; Essaw, Y.; Simpson, I.; Tan, V.; Sullivan, W. Rapid fluorescence-based screening for Wolbachia endosymbionts in Drosophila germ line and somatic tissues. Appl. Environ. Microbiol. 2011, 77, 4788-4794. [CrossRef]

95. Ferree, P.M.; Frydman, H.M.; Li, J.M.; Cao, J.; Wieschaus, E.; Sullivan, W. Wolbachia utilizes host microtubules and Dynein for anterior localization in the Drosophila oocyte. PLoS Pathog. 2005, 1, e14. [CrossRef]

96. Kramer, L.H.; Passeri, B.; Corona, S.; Simoncini, L.; Casiraghi, M. Immunohistochemical/immunogold detection and distribution of the endosymbiont Wolbachia of Dirofilaria immitis and Brugia pahangi using a polyclonal antiserum raised against WSP (Wolbachia surface protein). Parasitol. Res. 2003, 89, 381-386. [CrossRef]

97. Venard, C.M.; Crain, P.R.; Dobson, S.L. SYTO11 staining vs FISH staining: A comparison of two methods to stain Wolbachia pipientis in cell cultures. Lett. Appl. Microbiol. 2011, 52, 168-176. [CrossRef]

98. Fischer, K.; Beatty, W.L.; Jiang, D.; Weil, G.J.; Fischer, P.U. Tissue and stage-specific distribution of Wolbachia in Brugia malayi. PLoS Negl. Trop. Dis. 2011, 5, e1174. [CrossRef]

99. Sharma, R.; Al Jayoussi, G.; Tyrer, H.E.; Gamble, J.; Hayward, L.; Guimaraes, A.F.; Davies, J.; Waterhouse, D.; Cook, D.A.; Myhill, L.J.; et al. Minocycline as a re-purposed anti-Wolbachia macrofilaricide: Superiority compared with doxycycline regimens in a murine infection model of human lymphatic filariasis. Sci. Rep. 2016, 6, 23458. [CrossRef]

100. Mutafchiev, Y.; Bain, O.; Williams, Z.; McCall, J.W.; Michalski, M.L. Intraperitoneal development of the filarial nematode Brugia malayi in the Mongolian jird (Meriones unguiculatus). Parasitol. Res. 2014, 113, 1827-1835. [CrossRef]

101. Voronin, D.; Tricoche, N.; Jawahar, S.; Shlossman, M.; Bulman, C.A.; Fischer, C.; Suderman, M.T.; Sakanari, J.A.; Lustigman, S. Development of a preliminary in vitro drug screening assay based on a newly established culturing system for pre-adult fifth-stage Onchocerca volvulus worms. PLoS Negl. Trop. Dis. 2019, 13, e0007108. [CrossRef]

102. Bah, G.S.; Ward, E.L.; Srivastava, A.; Trees, A.J.; Tanya, V.N.; Makepeace, B.L. Efficacy of three-week oxytetracycline or rifampin monotherapy compared with a combination regimen against the filarial nematode Onchocerca ochengi. Antimicrob. Agents Chemother. 2014, 58, 801-810. [CrossRef]

103. Landmann, F.; Bain, O.; Martin, C.; Uni, S.; Taylor, M.J.; Sullivan, W. Both asymmetric mitotic segregation and cell-to-cell invasion are required for stable germline transmission of Wolbachia in filarial nematodes. Biol. Open 2012, 1, 536-547. [CrossRef]

104. Klarmann-Schulz, U.; Specht, S.; Debrah, A.Y.; Batsa, L.; Ayisi-Boateng, N.K.; Osei-Mensah, J.; Mubarik, Y.; Konadu, P.; Ricchiuto, A.; Fimmers, R.; et al. Comparison of Doxycycline, Minocycline, Doxycycline plus Albendazole and Albendazole Alone in Their Efficacy against Onchocerciasis in a Randomized, Open-Label, Pilot Trial. PLoS Negl. Trop. Dis. 2017, 11, e0005156. [CrossRef]

105. Agwuh, K.N.; MacGowan, A. Pharmacokinetics and pharmacodynamics of the tetracyclines including glycylcyclines. J. Antimicrob. Chemother. 2006, 58, 256-265. [CrossRef]

106. Specht, S.; Pfarr, K.M.; Arriens, S.; Hubner, M.P.; Klarmann-Schulz, U.; Koschel, M.; Sternberg, S.; Martin, C.; Ford, L.; Taylor, M.J.; et al. Combinations of registered drugs reduce treatment times required to deplete Wolbachia in the Litomosoides sigmodontis mouse model. PLoS Negl. Trop. Dis. 2018, 12, e0006116. [CrossRef] 
107. Specht, S.; Mand, S.; Marfo-Debrekyei, Y.; Debrah, A.Y.; Konadu, P.; Adjei, O.; Buttner, D.W.; Hoerauf, A. Efficacy of 2- and 4-week rifampicin treatment on the Wolbachia of Onchocerca volvulus. Parasitol. Res. 2008, 103, 1303-1309. [CrossRef]

108. Aljayyoussi, G.; Tyrer, H.E.; Ford, L.; Sjoberg, H.; Pionnier, N.; Waterhouse, D.; Davies, J.; Gamble, J.; Metuge, H.; Cook, D.A.N.; et al. Short-Course, High-Dose Rifampicin Achieves Wolbachia Depletion Predictive of Curative Outcomes in Preclinical Models of Lymphatic Filariasis and Onchocerciasis. Sci. Rep. 2017, 7, 210. [CrossRef]

109. Schiefer, A.; Schmitz, A.; Schaberle, T.F.; Specht, S.; Lammer, C.; Johnston, K.L.; Vassylyev, D.G.; Konig, G.M.; Hoerauf, A.; Pfarr, K. Corallopyronin A specifically targets and depletes essential obligate Wolbachia endobacteria from filarial nematodes in vivo. J. Infect. Dis. 2012, 206, 249-257. [CrossRef]

110. Schaberle, T.F.; Schiefer, A.; Schmitz, A.; Konig, G.M.; Hoerauf, A.; Pfarr, K. Corallopyronin A - a promising antibiotic for treatment of filariasis. Int. J. Med. Microbiol. 2014, 304, 72-78. [CrossRef]

111. Hoerauf, A.; Volkmann, L.; Nissen-Paehle, K.; Schmetz, C.; Autenrieth, I.; Buttner, D.W.; Fleischer, B. Targeting of Wolbachia endobacteria in Litomosoides sigmodontis: Comparison of tetracyclines with chloramphenicol, macrolides and ciprofloxacin. Trop. Med. Int. Health 2000, 5, 275-279. [CrossRef]

112. Prezioso, S.M.; Brown, N.E.; Goldberg, J.B. Elfamycins: Inhibitors of elongation factor-Tu. Mol. Microbiol. 2017, 106, 22-34. [CrossRef]

113. Hansen, J.L.; Ippolito, J.A.; Ban, N.; Nissen, P.; Moore, P.B.; Steitz, T.A. The structures of four macrolide antibiotics bound to the large ribosomal subunit. Mol. Cell 2002, 10, 117-128. [CrossRef]

114. von Geldern, T.W.; Morton, H.E.; Clark, R.F.; Brown, B.S.; Johnston, K.L.; Ford, L.; Specht, S.; Carr, R.A.; Stolarik, D.F.; Ma, J.; et al. Discovery of ABBV-4083, a novel analog of Tylosin A that has potent anti-Wolbachia and anti-filarial activity. PLoS Negl. Trop. Dis. 2019, 13, e0007159. [CrossRef]

115. Taylor, M.J.; von Geldern, T.W.; Ford, L.; Hubner, M.P.; Marsh, K.; Johnston, K.L.; Sjoberg, H.T.; Specht, S.; Pionnier, N.; Tyrer, H.E.; et al. Preclinical development of an oral anti-Wolbachia macrolide drug for the treatment of lymphatic filariasis and onchocerciasis. Sci. Transl. Med. 2019, 11. [CrossRef]

116. Turner, J.D.; Sharma, R.; Al Jayoussi, G.; Tyrer, H.E.; Gamble, J.; Hayward, L.; Priestley, R.S.; Murphy, E.A.; Davies, J.; Waterhouse, D.; et al. Albendazole and antibiotics synergize to deliver short-course anti-Wolbachia curative treatments in preclinical models of filariasis. Proc. Natl. Acad. Sci. USA 2017, 114, E9712-E9721. [CrossRef]

117. Li, Z.; Garner, A.L.; Gloeckner, C.; Janda, K.D.; Carlow, C.K. Targeting the Wolbachia cell division protein FtsZ as a new approach for antifilarial therapy. PLoS Negl. Trop. Dis. 2011, 5, e1411. [CrossRef]

118. Wu, B.; Novelli, J.; Foster, J.; Vaisvila, R.; Conway, L.; Ingram, J.; Ganatra, M.; Rao, A.U.; Hamza, I.; Slatko, B. The heme biosynthetic pathway of the obligate Wolbachia endosymbiont of Brugia malayi as a potential anti-filarial drug target. PLoS Negl. Trop. Dis. 2009, 3, e475. [CrossRef]

119. Lentz, C.S.; Halls, V.; Hannam, J.S.; Niebel, B.; Strubing, U.; Mayer, G.; Hoerauf, A.; Famulok, M.; Pfarr, K.M. A selective inhibitor of heme biosynthesis in endosymbiotic bacteria elicits antifilarial activity in vitro. Chem. Biol. 2013, 20, 177-187. [CrossRef]

120. Taylor, M.J.; Hoerauf, A.; Townson, S.; Slatko, B.E.; Ward, S.A. Anti-Wolbachia drug discovery and development: Safe macrofilaricides for onchocerciasis and lymphatic filariasis. Parasitology 2014, 141, 119-127. [CrossRef]

(C) 2019 by the authors. Licensee MDPI, Basel, Switzerland. This article is an open access article distributed under the terms and conditions of the Creative Commons Attribution (CC BY) license (http://creativecommons.org/licenses/by/4.0/). 